\title{
Interferon gamma protects neonatal neural stem/progenitor cells during measles virus infection of the brain
}

\author{
Kristen N. Fantetti, Erica L. Gray, Priya Ganesan, Apurva Kulkarni and Lauren A. O’Donnell
}

\begin{abstract}
Background: In the developing brain, self-renewing neural stem/progenitor cells (NSPC) give rise to neuronal and glial lineages. NSPC survival and differentiation can be altered by neurotropic viruses and by the anti-viral immune response. Several neurotropic viruses specifically target and infect NSPCS, in addition to inducing neuronal loss, which makes it difficult to distinguish between effects on NSPCs that are due to direct viral infection or due to the anti-viral immune response.
\end{abstract}

Methods: We have investigated the impact of anti-viral immunity on NSPCs in measles virus (MV)-infected neonates. A neuron-restricted viral infection model was used, where NSPCs remain uninfected. Thus, an anti-viral immune response was induced without the confounding issue of NSPC infection. Two-transgenic mouse lines were used: CD46+ mice express the human isoform of CD46, the MV entry receptor, under the control of the neuron-specific enolase promoter; CD46+/IFNY-KO mice lack the key anti-viral cytokine IFNy. Multi-color flow cytometry and Western Blot analysis were used to quantify effects on NSPC, neuronal, and glial cell number, and quantify effects on IFNy-mediated signaling and cell markers, respectively.

Results: Flow cytometric analysis revealed that NSPCs were reduced in CD46+/IFNY-KO mice at 3, 7, and 10 days post-infection (dpi), but were unaffected in CD46+ mice. Early neurons showed the greatest cell loss at $7 \mathrm{dpi}$ in both genotypes, with no effect on mature neurons and glial cells. Thus, IFNy protected against NSPC loss, but did not protect young neurons. Western Blot analyses on hippocampal explants showed reduced nestin expression in the absence of IFNY, and reduced doublecortin and BIII-tubulin in both genotypes. Phosphorylation of STAT1 and STAT2 occurred independently of IFNy in the hippocampus, albeit with distinct regulation of activation.

Conclusions: This is the first study to demonstrate bystander effects of anti-viral immunity on NSPC function. Our results show IFNy protects the NSPC population during a neonatal viral CNS infection. Significant loss of NSPCs in CD46+/IFNY-KO neonates suggests that the adaptive immune response is detrimental to NSPCs in the absence of IFNY. These results reveal the importance and contribution of the anti-viral immune response to neuropathology and may be relevant to other neuroinflammatory conditions.

Keywords: Anti-viral, Glia, Immune response, Interferon- $\gamma$, Measles virus, Neonate, Neurogenesis, Neural stem cell, STAT signaling

\footnotetext{
* Correspondence: odonnel6@duq.edu

Division of Pharmaceutical Sciences, Mylan School of Pharmacy, Duquesne

University, 600 Forbes Ave, Pittsburgh, PA 15282, USA
} 


\section{Background}

Central nervous system (CNS) viral infections during fetal and postnatal periods significantly alter neurodevelopment, leading to long-term cognitive deficits, blindness, hearing loss, and neurological disease [1-4]. Neurotropic viruses cause CNS damage by directly infecting and killing resident CNS cells (polio virus, Semliki Forest virus) and/ or by inducing an immune response that causes inflammation and encephalitis (measles virus, human immunodeficiency virus, cytomegalovirus, herpes simplex virus, West Nile virus) [5-10]. Ideally, the anti-viral immune response must carefully control a viral infection with minimal damage to non-renewable neurons. An excessive or prolonged inflammatory response can lead to bystanderinduced damage and can contribute to neuropathology $[11,12]$.

In the developing CNS, self-renewing neural stem precursor cells (NSPC) provide a pool of progenitor cells that can mature into functional neurons or glia [13]. Neuronal loss is a common pathological outcome of CNS infections, but effects on NSPC function may also contribute to viral-induced neuronal loss. Neurotropic viruses can disrupt the survival, proliferation, and maturation of NSPCs, which ultimately impairs neurogenesis. Lack of CNS repair may be caused by a deficit in the NSPCs pool, disrupted formation of new neurons from NSPCs, or changes in cell fate. Furthermore, some viruses specifically target NSPCs [14, 15]. Many studies that measured NSPC survival and differentiation during viral infections have done so with viruses that infect and replicate in NSPCs [16-18]. This makes it experimentally difficult to distinguish between which component contributes to neuropathology: primary viral infection or bystander inflammation.

The immune response in the CNS can non-cytolytically control viral replication and spread via anti-viral cytokines. IFN $\gamma$ is a pro-inflammatory cytokine produced by activated natural killer (NK) cells, natural killer T-cells (NKT), and T-cells and are required for non-cytolytic control of measles virus [19-21] and other neurotropic viruses [22-26]. During the anti-viral immune response, the release of proand anti- inflammatory cytokines also influences NSPC survival and neurogenesis [27, 28]. There is conflicting evidence as to whether IFN $\gamma$ is pro-neurogenic [29-32] or anti-neurogenic [33-37], depending on the age studied (neonate or adult), model system, and the presence or absence of the inflammatory response. Moreover, there is conflicting evidence as to whether IFNY induces apoptosis in neural cells, as human oligodendrocyte precursors are killed by IFN $\gamma$, but primary neurons are protected from other neurotoxic insults by IFNY signaling [38, 39].

We hypothesized that IFNY protects neonatal NSPCs during a CNS viral infection. To evaluate the effects of the anti-viral immune response on NSPCs and determine if loss of IFNy alters these effects, a transgenic mouse model of neuron-restricted measles virus (MV) infection was used. NSE-CD46+ mice express the human isoform of CD46, a receptor by which MV binds and enters cells. In this model, CD46 expression is driven by the neuronspecific enolase (NSE) promoter, restricting human CD46 expression and MV infection to mature CNS neurons [40]. In order to study the role of IFN $\gamma$, we also use CD46 + mice that have been backcrossed to IFN $\gamma$-KO mice (CD46+/IFN $\gamma-\mathrm{KO})$. Thus, modulations in NSPC function during MV infection can be examined with or without the contribution of IFN $\gamma$. Importantly, NSE is not expressed by NSPCs that express nestin [41], which spares NSPCs from MV infection in our model. Therefore, we are able to study the impact of the anti-viral immune response on NSPCs, without the confounding issue of direct viral infection of these cells.

Our study focuses on the fate of NSPCs that remain uninfected during a neonatal viral infection. Using the NSECD46+ model, we evaluated the bystander effects of the anti-viral immune response on NSPC function. Multicolor flow cytometry was used to quantify effects on the number of NSPCs, on cells specified to the neuronal lineage, and on cells specified to the glial lineage in vivo. We observed significant NSPC loss in MV-infected CD46 $+/ \mathrm{IFN} \gamma-\mathrm{KO}$ pups at 7 and $10 \mathrm{dpi}$, but not in the infected CD46+ pups, suggesting that IFN $\gamma$ protects NSPCs during a neuroinflammatory response. However, early neuronal cells were not protected; MV-infected CD46+ and CD46 $+/ \mathrm{IFN} \gamma-\mathrm{KO}$ pups both displayed loss of early neurons and a decrease in neurogenesis. Furthermore, mature neurons and cells specified to the glial lineage were unaffected during the course of infection. Signal transducers and activators of transcription-1 (STAT1), a key downstream signal transducer for IFN $\gamma$, was phosphorylated in hippocampal explants from both CD46+ and CD46+/IFN $\gamma-\mathrm{KO}$ pups, suggesting that other cytokines in the inflammatory response were contributing to STAT activity in the absence of IFN $\gamma$. These results are the first to indicate that IFNy protects NSPCs during a neonatal viral infection and furthers our understanding of what cell types are susceptible to the effects of the anti-viral immune response.

\section{Methods}

\section{Animals}

NSE-CD46+ and NSE-CD46+/IFN $\gamma-\mathrm{KO}$ transgenic mice were provided by Glenn Rall (Fox Chase Cancer Center) $[19,40]$. Animal use protocols (\#1408-10) were reviewed and approved by the Duquesne University Animal Care and Use Committee.

\section{Measles virus and BrdU injections}

MV-Edmonston was purchased from American Type Culture Collection (ATCC) and passaged and titred in 
Vero cells. On postnatal day 2 (P2), pups were intracerebrally injected with measles virus $\left(10^{4} \mathrm{PFU}\right.$ in a $10 \mu \mathrm{l}$ volume) using a $1 \mathrm{cc}$ syringe (BD Biosciences) and $27^{1 / 2} \mathrm{G}$ needle (BD Biosciences). Control pups were injected with an equal volume of media from mock-infected Vero cells. Twenty-four hours prior to being sacrificed on the indicated day post-infection (dpi), control and MV-infected mice were injected intraperitoneally with $50 \mu \mathrm{g} / \mathrm{g} \mathrm{5-}$ bromo-2'-deoxyuridine (BrdU; BD Biosciences), using a 1 -cc syringe and 30G x $1 / 2$-in needle (BD Biosciences).

\section{Dissociation of whole-brain tissue and flow cytometric analysis}

Mice were anesthetized with isoflurane, and entire brains were removed from control and MV-infected neonates on 3, 7, and 10 dpi. Whole-brain tissue was processed into single-cell isolates and labeled as described $[17,42]$, with modifications. Briefly, brain samples were dissociated into single-cell suspensions following incubation with TrypLE Select (Life Technologies)/200 U/ml DNaseI (Roche)/1 mM MgCl 2 (Life Technologies). Cell suspensions were filtered through $70 \mu \mathrm{m}$ and $40 \mu \mathrm{m}$ cell strainers (Fisher Scientific) and counted by trypan blue exclusion. Further, $10^{6}$ cells were labeled using the FITC BrdU Flow Kit (BD Biosciences) and the following antibodies: APC-A2B5 (1:10; Miltenyi Biotec), PE-CD24 (1:50; BD Biosciences), FITC BrdU (1:50; BD Biosciences), PE-Nestin (1:10; R\&D Systems), FITC-NeuN (1:50; Millipore), rabbit anti-doublecortin (DCX, 1:50; Santa Cruz Biotechnology Inc) and secondary fluorescent-conjugated goat anti-rabbit IgG-PE (1:100; eBioscience), rabbit anti-GFAP (1:250; Dako), and goat anti-rabbit IgG-PE (1:100; eBioscience) secondary. Labeling with cell surface markers (A2B5, CD24) was performed before fixation and permeabilization.

Cells were analyzed the same day on a BD Accuri $^{\mathrm{TM}}$ C6 flow cytometer (BD Biosciences). For each brain sample, 250,000 events were run for analysis. Dead cells and debris were excluded based on 7-AAD (BD Biosciences) staining as described [43, 44] (Additional file 1: Figure S1). Positively and negatively labeled cell populations and gating parameters were based on unlabeled and isotype controllabeled cells.

\section{Immunohistochemical analysis of brain tissue}

Control and MV-infected mice were anesthetized with isoflurane and perfused with $4 \%$ paraformaldehyde/PBS. Fixed brains were sliced along the midline and cryoprotected in a $30 \%$ sucrose/PBS solution at $4{ }^{\circ} \mathrm{C}$. Brains were immersed in tissue embedding compound (Fisher) and frozen in a dry ice/isopentane bath. Sagittal cryosections $(16 \mu \mathrm{M})$ were cut on the cryostat (Microm HM550, Thermo Scientific) and stored at $-80{ }^{\circ} \mathrm{C}$ until staining. Antigen retrieval was performed by heating the tissue for $30 \mathrm{~min}$ at $80{ }^{\circ} \mathrm{C}$ in a $10-\mathrm{mM}$ sodium citrate solution. Standard immunohistochemistry was performed to detect MV-infected cells (mouse anti-matrix protein and mouse anti-hemagglutinin, 1:400; Millipore), neural stem/progenitor cells (chicken anti-nestin for colabeling with MV (1:200; Novus Biologicals) or mouse anti-nestin for co-labeling with $\mathrm{NeuN}$ (1:400; Millipore)), and mature neurons (NeuN (guinea pig anti-NeuN) 1:500; Millipore). Sections were incubated with the primary antibody overnight at $4{ }^{\circ} \mathrm{C}$ in $4 \%$ goat serum/PBS. Then, the slides were washed $\times 3$ with PBS and incubated with the secondary antibody (goat anti-guinea pig-488, donkey anti-mouse-555, and goat anti-chicken-488; all at 1:000 from Thermo-Fisher) and Hoechst33342 stain (Molecular Probes) for $1 \mathrm{~h}$ at $25{ }^{\circ} \mathrm{C}$. For all histological analyses, at least three sagittal sections per brain were examined, and at least four mice per experimental group were assessed.

\section{Apoptosis in MV-infected brain tissue}

Brains from control and MV-infected mice (7 dpi) were collected following the procedure for the immunofluorescence assay. Sagittal brain sections were fixed in $3.7 \%$ formaldehyde and subjected to terminal deoxynucleotidyl transferase dUTP nick end labeling (TUNEL; (TdTFragEL DNA fragmentation detection kit; Millipore) using diaminobenzidine as a substrate. For counting of TUNEL-positive cells, four non-overlapping fields $(\times 20)$ were chosen by a blinded examiner moving dorsally to ventrally across the slice. TUNEL-positive cells were counted on an Olympus BX41 Laboratory Microscope (Olympus Corporation). Three sagittal slices were counted from each brain, with three mice assayed per condition. The average number of TUNEL-positive cells per $\times 20$ field \pm standard error was determined.

\section{Western Blot analysis on hippocampal explants}

Samples were processed and analyzed as described [45, 46], with modifications. For samples used for analysis of phosphorylated proteins, pups were perfused with $10 \mathrm{mM}$ sodium fluoride in ice cold $\times 1$ PBS prior to brain dissection in order to inactivate phosphatases [47]. The right and left hippocampus were dissected from each animal [48] and explants were combined, weighed, and sonicated in $\times 1$ cell lysis buffer (Cell Signaling Technologies) supplemented with Protease Inhibitor Cocktail (Sigma). Samples were sonicated for 5-10 pulses for 1-2 s each (Misonix Inc. Model XL2020). The total protein content of cell lysates was quantified using the Pierce ${ }^{\circ}$ BCA Protein Assay Kit (ThermoScientific) and the 1420 Multilabel Counter Victor3 plate reader (Perkin Elmer). Twenty micrograms of total protein was loaded for all proteins but STAT2 and STAT2-P (40 $\mu \mathrm{g}$ was loaded). Proteins were separated on NuPAGE $7 \%$ Tris-Acetate (Nestin, STAT1, STAT1-P, STAT2, STAT2-P, STAT3, 
STAT3-P; Invitrogen) or NuPAGE $10 \%$ Bis-Tris (GFAP, DCX, BIII-tubulin; Invitrogen) gels and semi-dry transferred (BioRad TransBlot Semi-Transfer Cell) to immobilon-FL membranes (Millipore). Membranes were incubated in $50 \%$ odyssey blocking buffer (LI-COR Biosciences) in $0.1 \% \mathrm{PBS} / \mathrm{Tween}$ (PBS/Tw; Sigma) for $30 \mathrm{~min}$ at room temperature, washed in $\mathrm{PBS} / \mathrm{Tw}$ and incubated in the following primary antibodies, diluted in blocking solution, overnight at $4{ }^{\circ} \mathrm{C}$ on a shaker: mouse anti-nestin (1:250; Millipore), rabbit anti-DCX (1:1,000; Abcam), rabbit anti- $\beta$ III-tubulin (1:1,000; Cell Signaling Technologies), rabbit anti-GFAP (1:1,000; Dako), rabbit anti-STAT1 (1:1,000; BD Biosciences), mouse antiSTAT1-P (1:1,000; BD Biosciences), rabbit anti-STAT2 (1:1,000; Millipore), rabbit anti-STAT2-P (1:500; Millipore), mouse anti-STAT3 (1:2500; BD Biosciences), rabbit anti-STAT3-P (1:1,000; Cell Signaling Technologies), mouse anti-GAPDH (1:10,000; Millipore), and rabbit anti-GAPDH (1:3,000; Cell Signaling Technologies). Membranes were washed three times in $\mathrm{PBS} / \mathrm{Tw}$, incubated with secondary antibodies (infrared 800 or $700 \mathrm{~nm}$ anti-rabbit or anti-mouse 1:10,000; LI-COR Biosciences) diluted in blocking solution, for $1 \mathrm{~h}$ at room temperature and washed again in $\mathrm{PBS} / \mathrm{Tw}$. Membranes were imaged and quantified with the Odyssey Infrared Imager (LI-COR Biosciences). Protein levels were normalized to GAPDH as a protein loading control.

\section{Statistical Analysis}

Data are presented as the mean \pm standard error (SE). Means represent data from a minimum of three independent experiments of 3-6 neonates for flow cytometry experiments and a minimum of four hippocampal explants for Western Blot experiments. Comparisons between control and MV-infected experimental groups in flow cytometry experiments were performed by three-way ANOVA followed by a Tukey's multiple-comparison test, using SPSS statistics (IBM). Comparisons made in TUNEL assays and Western Blot experiments were performed by two-way ANOVA followed by a Tukey's multiplecomparison test using GraphPad Software (GraphPad, Inc.). A $p$ value of less than 0.05 was considered statistically significant.

\section{Results}

IFNy protects neural stem/progenitor cells (NSPCs), but not early neurons, during viral infection of the neonatal brain

We first confirmed that MV infection is limited to CNS neurons in CD46+ neonates. Previous studies have demonstrated that MV antigen co-localizes with neuronal markers, but co-localization with markers for NSPCs (nestin) has not been investigated previously. MV+ cells were noted in the thalamus, hippocampus, and cerebellum early in infection (3 days post-infection (dpi); data not shown), with subsequent MV spread in the cerebral cortex at other time points (7-10 dpi, Fig. 1). Nestin + cells were found in the vicinity of MV+ cells in multiple brain regions (Fig. 1, $\mathrm{a}-\mathrm{i})$; however, nestin and MV staining did not co-localize in any cells. Markers for mature neurons (NeuN, J-L) showed nuclear staining of MV+ cells, demonstrating that MV infection is limited to mature neurons.

We investigated whether a lack of IFNY might impact the proportion of NSPCs or cells specified to the neuronal lineage during the course of infection. CD46+ and $\mathrm{CD} 46+/ \mathrm{IFN} \gamma$-KO pups were mock or MV-infected on postnatal day 2 (P2) and whole brains were harvested at 3,7 , or 10 days post-infection (dpi). The study endpoints reflect different phases of disease progression and correspond to when the specific arms of the immune system are active in the CD46+ model in both adults and neonates (unpublished observations and [49]). Three dpi corresponds to the initial phase of infection when the innate immune response predominates, including infiltration of IFN $\gamma$-producing natural killer (NK) cells. This is also the first day of detectable MV antigen and T-cell infiltration in the CNS [49]. At $7 \mathrm{dpi}$, the adaptive immune response predominates with peak infiltration of IFN $\gamma$ producing T-cells $[49,50]$. Peak T-cell infiltration continues until $10 \mathrm{dpi}$, when severe signs of clinical disease and death occur in neonates.

Cell isolates from whole brains were labeled with markers for multipotent neural stem/progenitor cells (nestin), immature neurons (CD24, doublecortin (DCX)), and mature neurons (NeuN), and multi-color flow cytometry was used to quantify the percentage of positively labeled cells. We observed an age-dependent decrease in the percentage of NSPCs (A, E) and early neurons (B, C, F, G), and an age-dependent increase in $\mathrm{NeuN}+$ mature neurons $(\mathrm{D}, \mathrm{H})$ in both $\mathrm{CD} 46+$ and $\mathrm{CD} 46+/ \mathrm{IFN} \gamma-\mathrm{KO}$ genotypes (Fig. 2). Therefore, the percentage of positively labeled cells was compared between control and MV-infected brains at each dpi within each mouse genotype.

Overall, we observed significantly greater NSPC and immature neuron cell loss in MV-infected pups that lack IFN $\gamma(\mathrm{CD} 46+/ \mathrm{IFN} \gamma-\mathrm{KO}$; Fig. 2e-g) compared to CD46+ pups (Fig. $2 \mathrm{a}-\mathrm{c}$ ) by three-way ANOVA $(p<0.001)$. The percentage of nestin + cells was reduced at $3 \mathrm{dpi}$, the first day of detectable MV antigen and T-cell infiltration in the CNS, and was significantly decreased at 7 and $10 \mathrm{dpi}$ (Fig. 2e) in CD46+/IFN $\gamma$-KO pups, when the adaptive immune response and T-cell infiltration peak [49]. In contrast, nestin+ cells were maintained at all dpi in CD46+ mice in comparison to mock-infected mice (Fig. 2a), suggesting that IFN $\gamma$ preserves this population during a CNS viral infection.

CD24+ and DCX+ immature neurons were most vulnerable to cell loss in CD46+ MV-infected brains at 7 and 

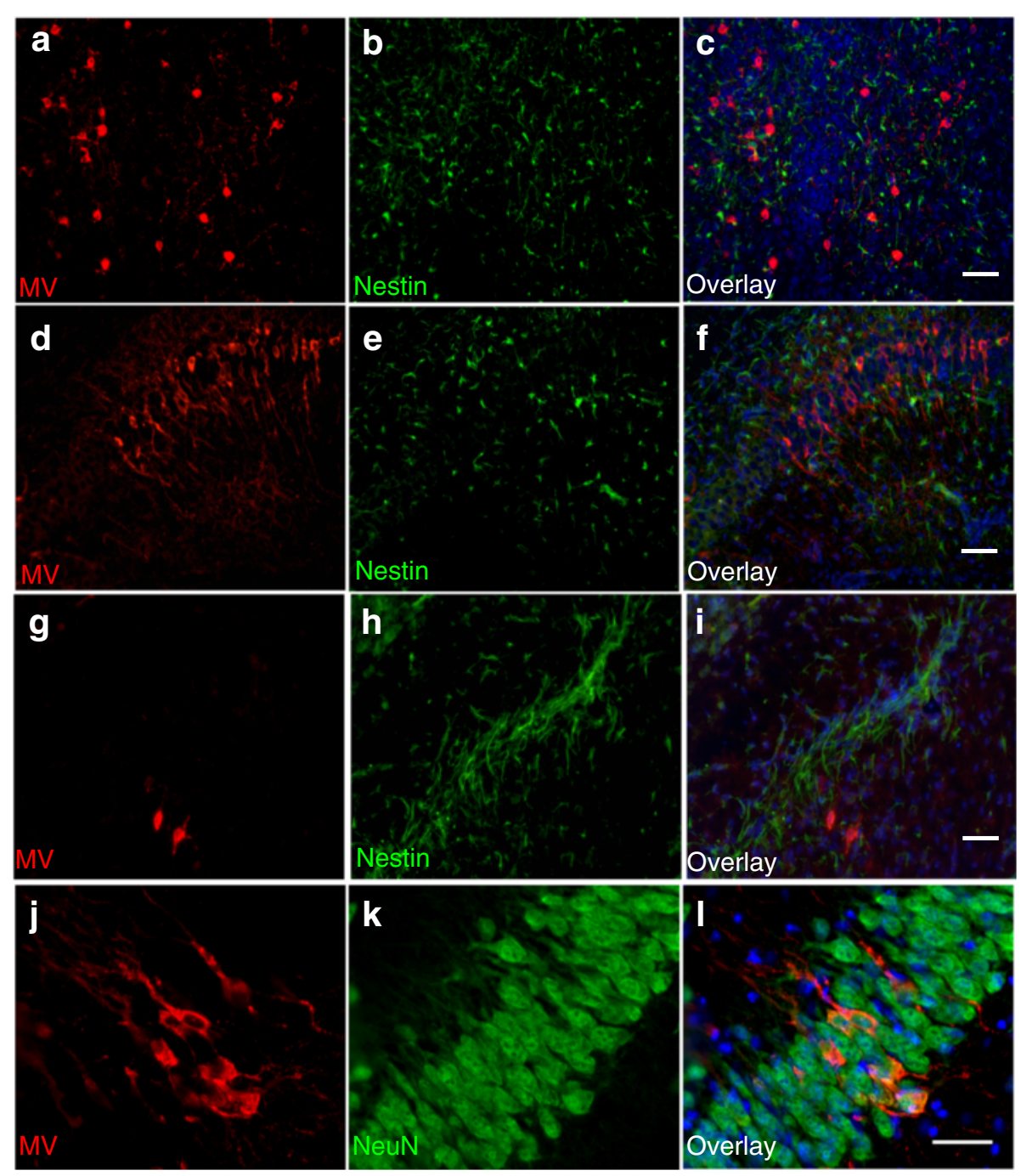

Fig. 1 MV infects neurons, but not NSPCS, in CD46+ mice. Sagittal brain sections from MV-infected CD46+ mice were collected at 10 days postinfection (dpi) and stained for MV (red) and nestin (green; $\mathbf{a}-\mathbf{i}$ ) or MV (red) and NeuN (green; j-I). All sections were stained with Hoechst (blue) to visualize nuclei. Representative images are shown from different brain regions, including the thalamus (a-c), CA1 region of the hippocampus $(\mathbf{d}-\mathbf{f})$, fiber tracts of the medial forebrain bundle system $(\mathbf{g}-\mathbf{i})$, and the dentate gyrus $(\mathbf{j}-\mathbf{I})$. MV staining was restricted to NeuN+ cells $(\mathbf{j}-\mathbf{I})$. Co-localization with nestin and MV was not observed in any brain region $(\mathbf{a}-\mathbf{i})$. Panels $\mathbf{a}-\mathbf{i}$ : Magnification $=\times 20 ;$ scale bar $=50 \mu \mathrm{m}$. Panels $\mathbf{j}-\mathbf{I}$ : Magnification $=\times 40$; scale bar $=25 \mu \mathrm{m}$

10 dpi (Fig. 2b, c), but were lost at all dpi in MV-infected IFN $\gamma$-KO mice (Fig. 2f, g). Furthermore, the reduction in the percentage of CD24+ and DCX+ cells at 7 dpi was nearly twofold greater in $\mathrm{CD} 46+/ \mathrm{IFN} \gamma-\mathrm{KO}$ pups compared to CD46+ pups. When the percent change in positively labeled cells was compared between control and MV-infected animals at $7 \mathrm{dpi}$, IFNy-KO mice displayed a 53 and $37 \%$ decrease in CD24+ and DCX+ cells, respectively (Fig. 2f, g), compared to CD46+ mice (CD24+ $22 \%$; $\mathrm{DCX}+20 \%$; Fig. 2b, c). Conversely, there was no significant difference in the percentage of NeuN+ mature neurons, between control and MV-infected brains at all dpi, in both genotypes (Fig. 2d, h). From these results, we suspect that the anti-viral immune response is detrimental to
NSPCs and that IFNY may be protective against the detrimental effects of the immune response for NSPCs during a neonatal viral infection.

\section{Loss of IFN $\gamma$ does not alter glial differentiation}

CNS viral infections are often associated with increased glial activation and/or impaired glial function. Manchester et al. [50] reported widespread glial activation and astrocytic GFAP staining in MV-infected NSE-CD46+ pups at $7 \mathrm{dpi}$, leading us to speculate that the reduction in NSPC and neuronal cell number may be attributed to NSPCs being specified to the glial lineage and adopting a glial cell fate in MV-infected brains. Additionally, microglia and astrocytes are IFN $\gamma$-responsive, suggesting there may be 


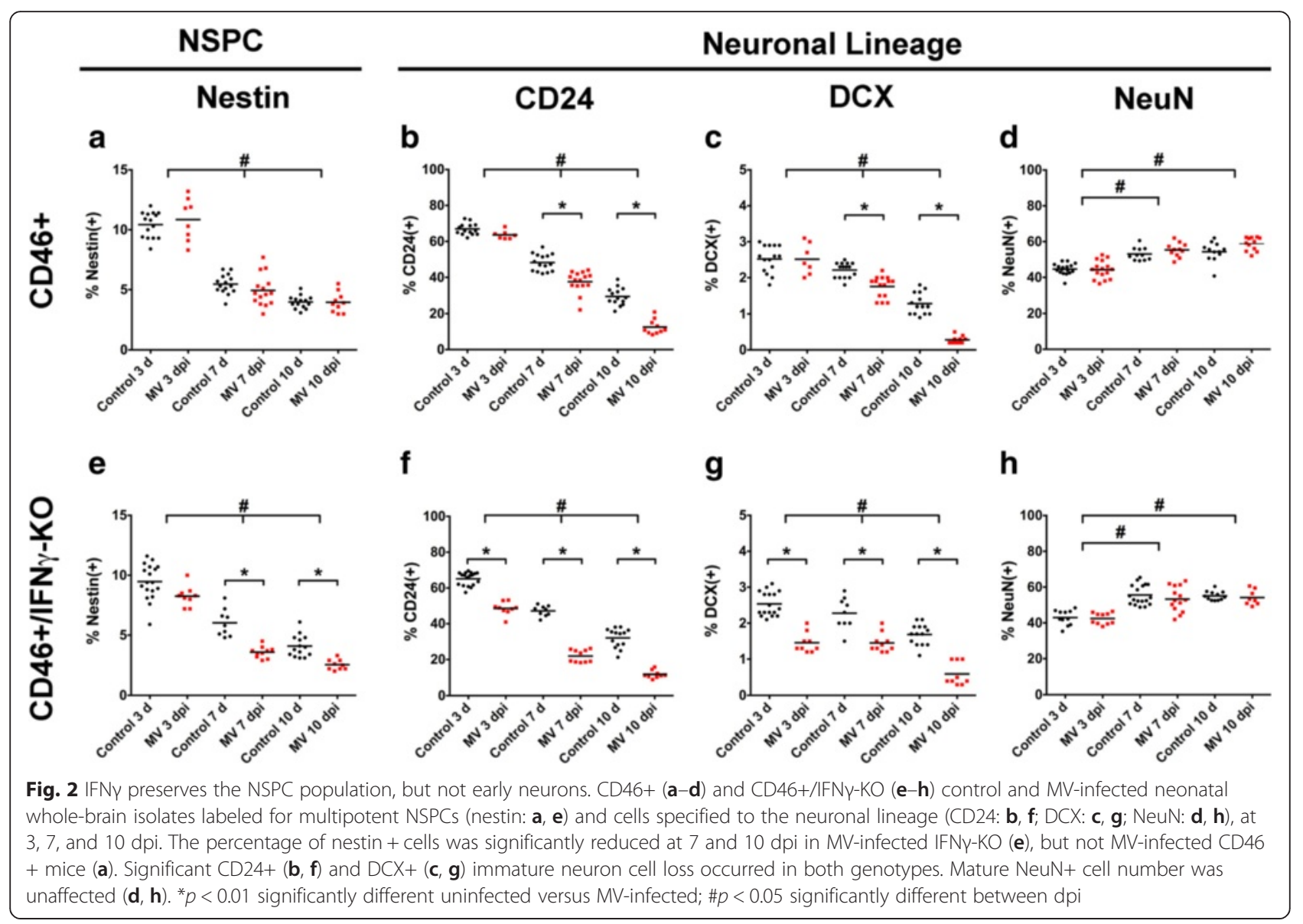

IFN $\gamma$-dependent effects on glial function [11, 51]. We evaluated whether the anti-viral immune response and a lack of IFNY impacted glial cell number. Cell isolates from mock- and MV-infected brains were labeled with A2B5, O4, or GFAP, and flow cytometry was used to quantify the percentage of glial precursors, oligodendrocytes, and astrocytes, respectively. Overall, glial cell number between control and MV-infected brains from CD46+ (Fig. 3a-c) and $\mathrm{CD} 46+/ \mathrm{IFN} \gamma-\mathrm{KO}$ (Fig. 3e-g) pups was unaffected at all dpi examined. Age-related differences in A2B5+ glial precursors (Fig. 3a) and O4+ oligodendrocytes (Fig. 3b, f) were observed in the presence and absence of the virus. Unexpectedly, we did not observe a significant effect on the percentage of GFAP+ cells (Fig. 3c, g) nor on the expression level of GFAP (Fig. 3d, h; MFI: Mean Fluorescent Intensity) between control and MV-infected pups in both types of mice, suggesting that there was minimal reactive gliosis in the whole brain. From these results, we concluded that the reduction in NSPC and early neuronal cell number was not due to NSPCs adopting a glial cell fate and next considered whether the loss of NSPCs and early neurons was due to effects on cell proliferation and/or aberrant neuronal differentiation.

\section{MV infection and loss of IFN $\gamma$ do not alter BrdU uptake by nestin+ cells}

IFN $\gamma$ has been shown to either promote or inhibit NSPC proliferation and can regulate neurogenesis [30, 31, 33, $34,36,52-55]$. One mechanism by which IFN $\gamma$ may preserve the NSPC pool in CD46+ mice is by promoting NSPC proliferation. Similarly, the loss of early neurons may be attributed to either a lack of early neuron/neuroblast proliferation and/or impaired neuronal differentiation. We characterized the effects of MV infection and loss of IFN $\gamma$ on the proliferation of nestin+, CD24+, and $\mathrm{DCX}+$ cells, by isolating cells from pups that were injected with BrdU $24 \mathrm{~h}$ prior to harvest to label actively dividing cells. The proportion of BrdU+ cells within each cell population was quantified by flow cytometry.

Reduced BrdU uptake was observed in MV-infected $\mathrm{CD} 46+/ \mathrm{IFN} \gamma-\mathrm{KO}$ pups at 3 and $7 \mathrm{dpi}$ compared to uninfected mice (Fig. 4d) and CD46+ pups at the same time points (Fig. 4a). However, the \%BrdU+ cells within the nestin+ cell population showed no significant difference between control and MVinfected pups in both genotypes (Fig. 4b, e), suggesting that the loss of nestin+ cells in $\mathrm{CD} 46+/ \mathrm{IFN} \gamma-\mathrm{KO}$ 


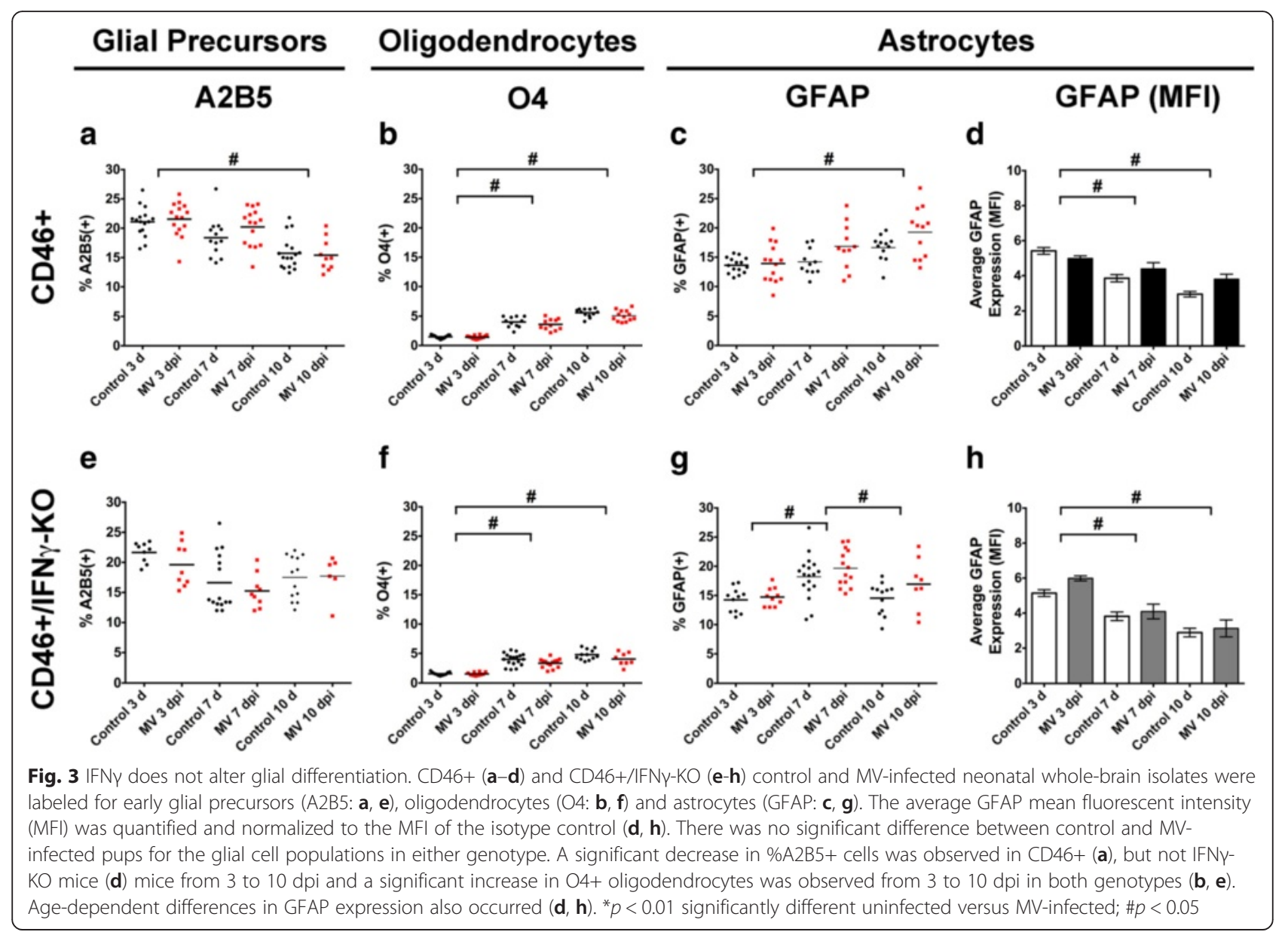

mice (Fig. 4e) is not due to impaired proliferation of the NSPC pool.

To evaluate whether neuronal differentiation was affected, we quantified the percentage of BrdU+ cells within the early neuronal CD24+ (Fig. 4c, f) and DCX+ populations (not shown). We were unable to detect BrdU-DCX double-positive cells by flow cytometry, suggesting that either the DCX+ cell population is too small in number to detect a small fraction of the cells that may have taken up BrdU (less than $3 \%$ of cell isolate is $\mathrm{DCX}+$; Fig. 2c, g) or that this population is more mature than the CD24+ population and that fewer DCX+ cells are proliferating at the time points examined. BrdU uptake was significantly reduced within the CD24+ population at $10 \mathrm{dpi}$ in MV-infected CD46+ (Fig. 4c) and CD46 $+/$ IFN $\gamma$-KO mice (Fig. 4f), corresponding to when severe signs of illness and morbidity occur in this model.

These results suggest that IFNY does not directly maintain the NSPC population through enhanced proliferation and that the loss of nestin + cells in CD46 $+/ \mathrm{IFN} \gamma-\mathrm{KO}$ mice is not due to impaired proliferation. Additionally, it is unlikely that the reduction in nestin+ cells is due to NSPCs being promoted to the neuronal lineage, as CD24+ and DCX+ populations are reduced and not increased, as would be expected with NSPCs adopting a neuronal cell fate.

\section{MV infection induces widespread apoptosis in brain tissue}

IFN $\gamma$ may protect against toxic insults or induce apoptosis, depending on the type of neural cell $[36,38]$. If IFNY contributed to protection of NSPCs in the CD46+ model, then we would predict greater apoptosis in CD46 $+/$ IFN $\gamma$-KO mice during infection. To test whether IFN $\gamma$ was associated with less apoptosis, we performed TUNEL stains on brain tissue from MV-infected mice (7 dpi). Significant TUNEL reactivity was found throughout the brains of MV-infected mice in comparison to uninfected controls (Fig. $5 \mathrm{a}-\mathrm{c}$ ). No significant differences were found between $\mathrm{CD} 46+$ and $\mathrm{CD} 46+/ \mathrm{IFN} \gamma-\mathrm{KO}$ mice, suggesting that IFNY does not reduce the number of cells undergoing apoptosis across the whole brain. We further examined brain tissue for staining of NeuN (mature neurons; green) and nestin (NSPCs, red) to assess if differences in neuronal health could be observed. Overall, we did not observe changes in the morphology of 


\section{$\operatorname{BrdU}(+) \quad$ BrdU(+) Nestin(+) BrdU (+) CD24(+)}

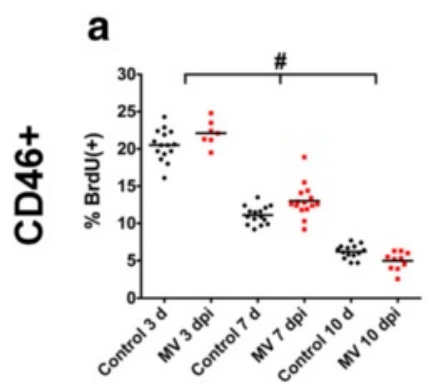

b

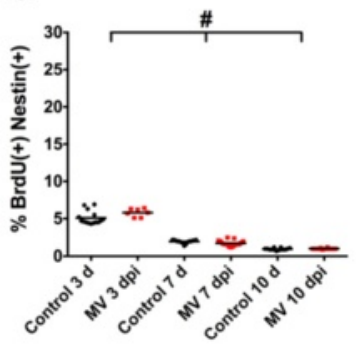

e
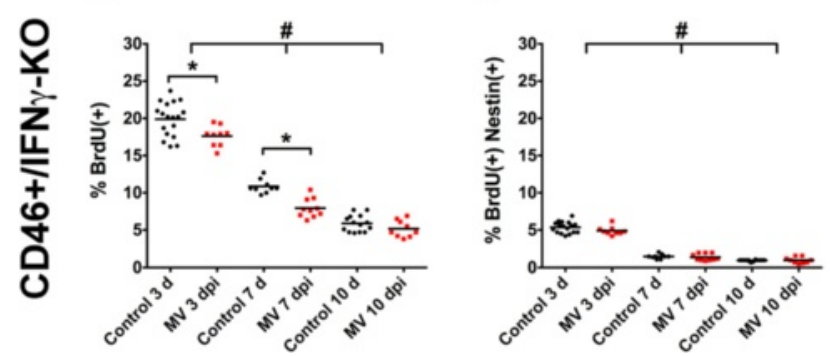

C

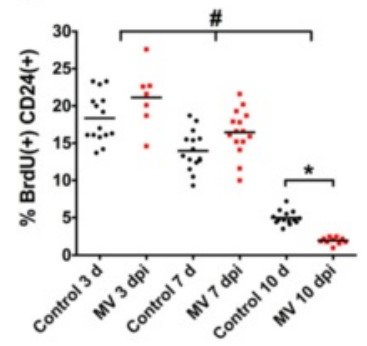

f

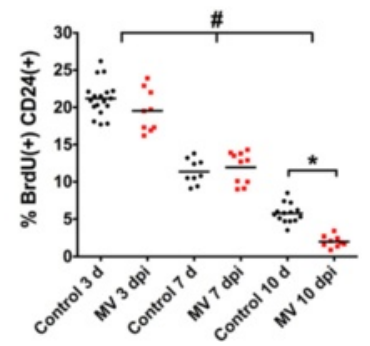

Fig. $4 \mathrm{MV}$ infection does not alter BrdU uptake by NSPCs. CD46+ (a-c) and CD46+/IFNy-KO (d-f) pups were injected with BrdU $24 \mathrm{~h}$ before whole-brain isolates were processed and labeled for BrdU+ cells $(\mathbf{a}, \mathbf{d})$, or BrdU(+)Nestin(+) (b, e), and BrdU(+)CD24(+) (c, $\mathbf{f})$ double-positive cells. Reduced BrdU uptake was observed in MV-infected CD46+/IFNY-KO pups at 3 and 7 dpi (d), but not CD46+ mice (a). BrdU+ cells within the Nestin+ population showed no significant difference between control and MV-infected pups in both genotypes, but a significant reduction with age $(\mathbf{b}, \mathbf{e})$. The percentage of BrdU+ cells within the CD24+ cell population was reduced at $10 \mathrm{dpi}(\mathbf{c}$, $\mathbf{f})$, when severe illness and death occurs. ${ }^{*} p$ $<0.01$ significantly different uninfected versus MV-infected; \#p $<0.05$ significantly different between dpi

the hippocampal formation (Fig. $5 \mathrm{~d}-\mathrm{g}$ ) or cortex (not shown). These results demonstrate that although apoptosis is seen throughout the brain during infection, the level of cell death is not sufficient to cause marked changes in the structure of the brain.

\section{IFNץ preserves NSPC, but not neuronal, markers within the hippocampus during infection}

Immunohistochemical staining for MV matrix and nucleocapsid proteins showed widespread MV-infection at 7 dpi (not shown) that was restricted to neuronal cell bodies and axonal processes. Although the infection was widespread, the hippocampus and surrounding area consistently displayed a "hot-spot" or focal area of MV-infected neurons at later dpi, compared to other brain regions, as has been noted previously [40]. As well, an increase in TUNEL+ apoptotic cells in the dentate gyrus of the hippocampus was reported at $7 \mathrm{dpi}$ [50], suggesting that in addition to being a neurogenic region rich in NSPCs, the hippocampus is susceptible to the effects of and negatively impacted by MV infection. To evaluate effects on various cell types within the hippocampus, we attempted to isolate cells from neonatal hippocampal explants, but due to technical limitations we were unable to isolate enough cells for cell labeling and flow cytometry. Instead, we performed Western Blot analysis on neonatal hippocampal explants in order to evaluate changes in cell marker protein levels.

Changes in protein level in the hippocampus reflected changes in cell numbers that were measured by flow cytometry for NSPCs and immature neurons. MV-infected $\mathrm{CD} 46+/ \mathrm{IFN} \gamma-\mathrm{KO}$ explants displayed significantly lower nestin expression (Fig. 6e) compared to MV-infected CD46+ mice (Fig. 4a), which displayed no change with infection. Furthermore, there was a significant reduction in DCX protein at $7 \mathrm{dpi}$, not $3 \mathrm{dpi}$, in CD46+ pups (Fig. 6b), whereas DCX levels were reduced at all time points in $\mathrm{CD} 46+/ \mathrm{IFN} \gamma-\mathrm{KO}$ mice (Fig. 6f). BIII-tubulin levels were higher at $7 \mathrm{dpi}$ compared to $3 \mathrm{dpi}$ in both genotypes consistent with continued maturation of neurons; however, a significant decrease in BIII-tubulin was observed at $7 \mathrm{dpi}$ in $\mathrm{MV}$-infected explants, suggesting that the viral infection is detrimental to mature neurons, in addition to NSPCs (Nestin; Fig. 2a, e) and young neurons (DCX; Fig. 2b, f), in the hippocampus. The $\beta$ IIItubulin results contrast that observed for \%NeuN+ cells quantified by flow cytometry (Fig. 2d, h), where no effect on mature neuron cell number was observed across the whole brain. GFAP levels were elevated significantly with infection in $\mathrm{CD} 46+$ mice, but not in $\mathrm{CD} 46+/ \mathrm{IFN} \gamma-\mathrm{KO}$ 

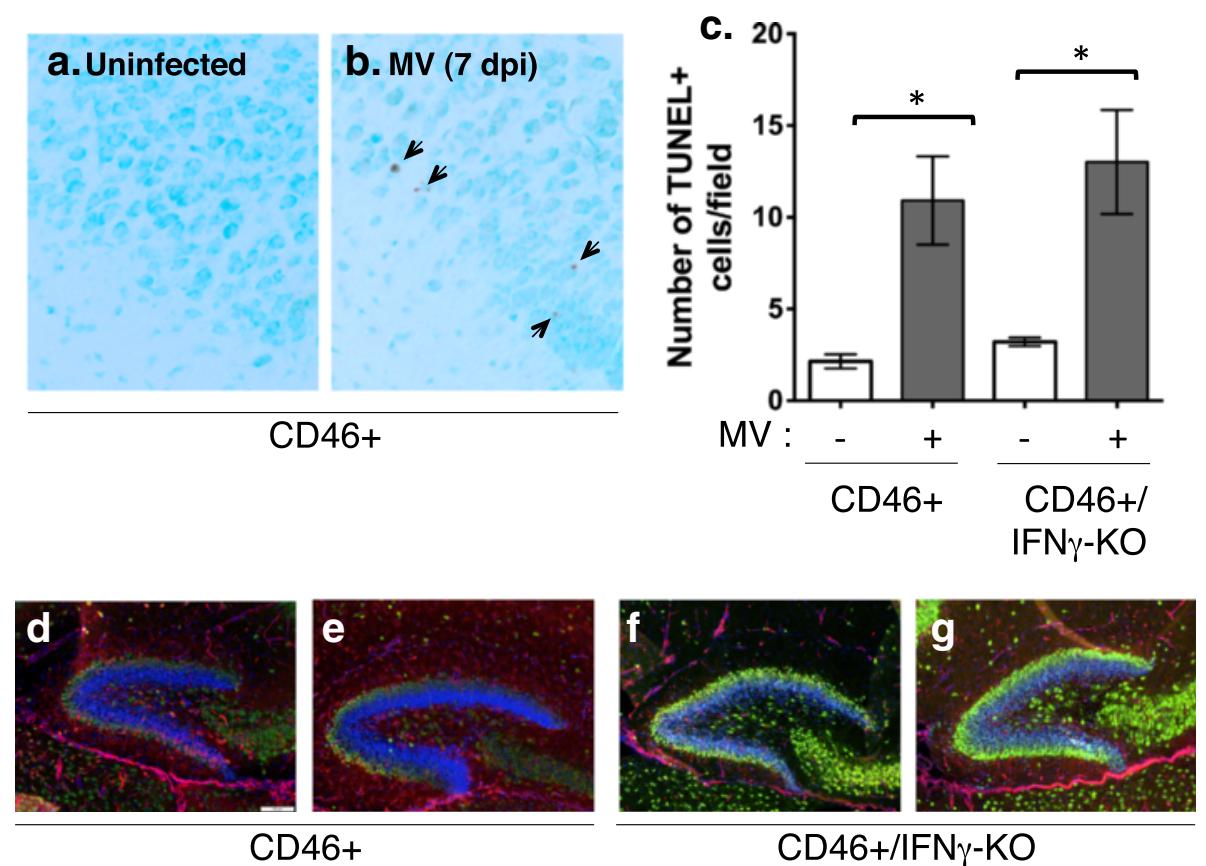

Fig. $5 \mathrm{MV}$ infection induces extensive apoptosis, but does not alter nestin localization. CD46+ and CD46+/IFNy-KO brains were assayed by TUNEL $(\mathbf{a}-\mathbf{c})$ or immunohistochemistry for nestin and NeuN at $7 \mathrm{dpi}(\mathbf{d}-\mathbf{g})$. The average TUNEL+ cells per field (four fields per slice) were averaged from three different sagittal sections per mouse (c $; n=3$ mice per condition). Significant increases in TUNEL+ cells were seen during infection in both genotypes, but no significant difference was observed between genotypes ( $\mathbf{c}_{;}^{*} p<0.01$ significantly different uninfected versus MV-infected). Nestin (red) and NeuN (green) staining was observed in the hippocampus at $7 \mathrm{dpi}$ in both CD46+ (d, e) and CD46+/IFNy-KO (f, g) mice during infection (scale bar $=100 \mu \mathrm{m}$ )

mice, in comparison to uninfected controls at $7 \mathrm{dpi}$, suggesting that localized reactive astrogliosis may be occurring in the hippocampus in the presence of IFNy during infection (Fig. 6d, h). As a measure of viral load, we also quantified levels of MV protein using a polyclonal human antiserum (Fig. 7a). MV protein expression increased over the course of infection, with no significant difference in viral protein levels detected between genotypes (Fig. 7b). Thus, the differences we observed in levels of neural expression markers are not likely to be due to variances in viral load between the genotypes. Together, these results provide a secondary measure of cell protein content and validate the flow cytometry results within a neurogenic region of the brain that consistently carries a high viral load.

\section{STAT1 phosphorylation in the hippocampus occurs independently of IFN $\gamma$ during MV infection}

Since IFN $\gamma$ affected neural cell marker expression in the hippocampus (Fig. 6) and the whole brain (Fig. 2; NSPC and neuron loss), we evaluated which IFN-signaling pathways are activated in the hippocampus during a viral infection. Type I interferons (IFN $\alpha$ and IFN $\beta$ ) activate STAT1 and STAT2 proteins via phosphorylation and are required for early control of a viral infection. IFN $\gamma$, a Type II interferon, predominately activates STAT1, but can also activate STAT3 in neurons [56] and NSPCs [57]. In particular, IFNY is required for long-term control of neurotropic viruses in CD46+ adult mice and other infection models $[22,58]$. Thus, we analyzed hippocampal explants for expression of STAT1-3 and activation of the STAT proteins via phosphorylation.

Hippocampal tissue lysates were analyzed for total (STAT) and phosphorylated (STAT-P) forms of STAT proteins that are activated by IFN $\alpha / \beta$ (STAT1, STAT2) and IFNY (STAT1, STAT3) (Figs. 8 and 9). STAT1 is expressed as two isoforms; STAT1 $\alpha$, which exhibits DNA binding activity, and STAT1 $\beta$, which lacks a DNA binding domain and acts as negative regulator of STAT $1 \alpha$. Each isoform of STAT1 was assayed independently in Fig. 8. Total STAT1 expression and STAT1 phosphorylation was unchanged at $3 \mathrm{dpi}$ in both genotypes. In CD46+ explants, STAT1 $\alpha$ was significantly activated via phosphorylation above untreated controls at 7 and $10 \mathrm{dpi}$ (Fig. $8 \mathrm{~b}$ ), whereas STAT1 $\beta$ was significantly activated at $7 \mathrm{dpi}$ (Fig. 8c) when normalized to GAPDH. $\mathrm{CD} 46+/ \mathrm{IFN} \gamma$-KO explants also demonstrated activation of STAT $1 \alpha$ and STAT1 $\beta$, with significant activation of both isoforms at $10 \mathrm{dpi}$ (Fig. 8g, h). Total levels of STAT1 expression increased at later time points postinfection in both genotypes. CD46+ explants showed significantly more expression of total STAT $1 \alpha$ and $\beta$ at 


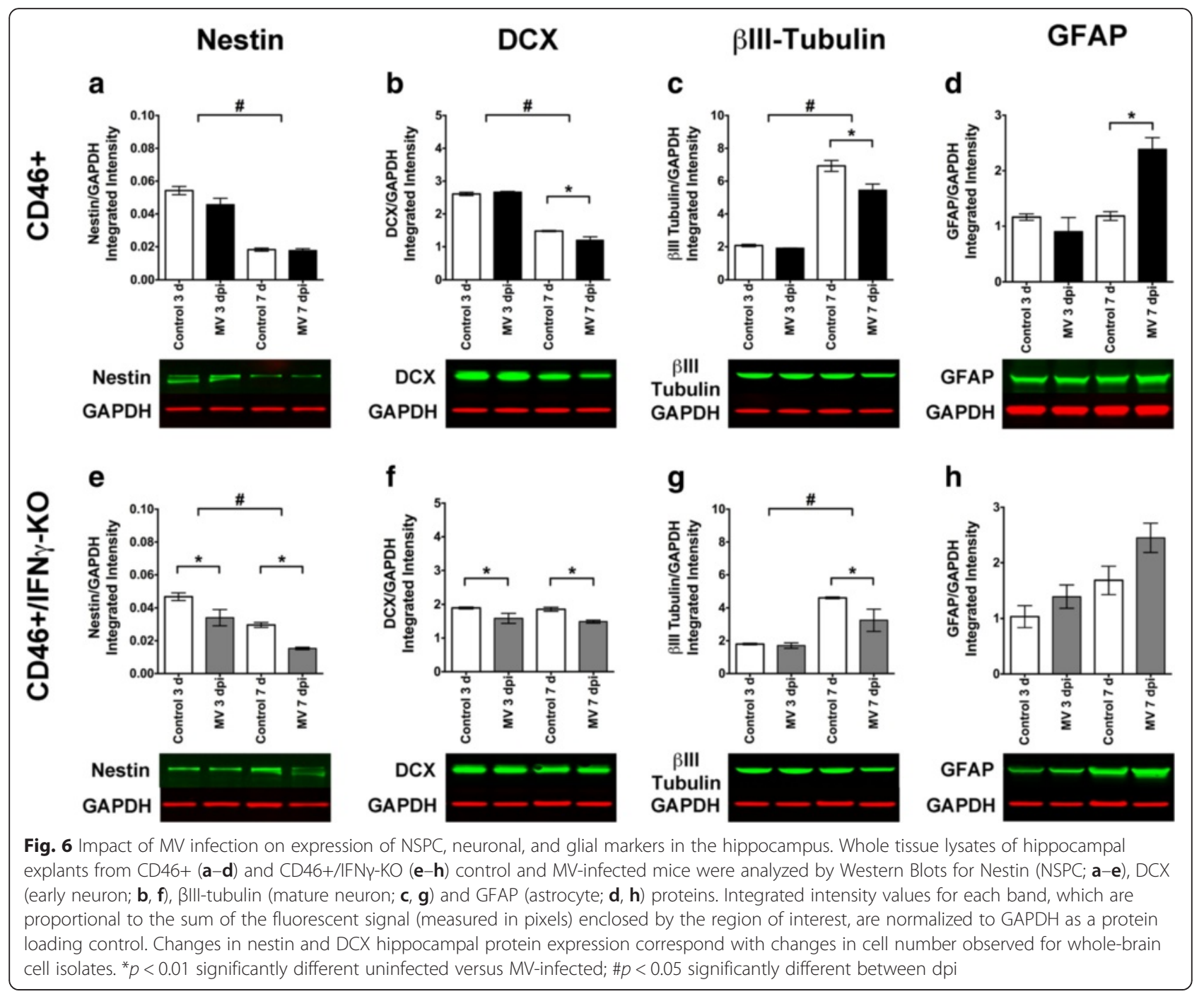

both 7 and 10 dpi (Fig. 8d, e), while significantly higher expression of total STAT1 was only observed at $10 \mathrm{dpi}$ in the absence of IFNY (Fig. 8i, j). These results demonstrate that phosphorylation of STAT1 occurs in hippocampal tissue in the absence of IFN $\gamma$ during infection, potentially through expression of Type I IFNs. Protein ratios of STAT1-P/STAT1 revealed distinct regulation of STAT1 phosphorylation between genotypes that was isoform dependent (Fig. 8f, g, m, n). CD46+ mice showed a significant increase in the STAT $1 \alpha-\mathrm{P} / \mathrm{STAT} 1 \alpha$ ratio at 10 $\mathrm{dpi}$, which was absent at all time points in the absence of IFN $\gamma$. Moreover, STAT1 $\beta-P / S T A T 1 \beta$ ratios declined during infection in $\mathrm{CD} 46+/ \mathrm{IFN} \gamma-\mathrm{KO}$ explants, but not CD46+ explants. These data suggest IFNy drives an increase in phosphorylation of the available STAT $1 \alpha$ in the cell, although increased expression of both STAT1 isoforms occurs independently of IFN $\gamma$.

We further explored the activation of other STAT molecules (STAT2 and STAT3) that have been implicated as alternative signaling pathways downstream of IFN $\gamma[56,59]$ (Fig. 9). STAT2 phosphorylation is induced in CD46+ explants at 7 and 10 dpi by MV infection (Fig. 9b), whereas significant phosphorylation of STAT2 was only seen at 7 dpi in CD46+/IFN $\gamma$-KO explants (Fig. 9c) when normalized to GAPDH. Total expression of STAT2 did not change significantly with infection in either genotype (Fig. 9d, e). However, total STAT2 levels increased independently of infection over time in CD46+ explants (Fig. 9d). Protein ratios of STAT2-P/STAT2 revealed increased activation of phosphorylation of STAT2 in CD46+ mice, with a trend toward increased regulation in $\mathrm{CD} 46+/ \mathrm{IFN} \gamma-\mathrm{KO}$ mice (Fig. 9f, g). In contrast, STAT3 activation did not increase with infection (Fig. 9i, j, m, n). Total STAT3 expression increased at $10 \mathrm{dpi}$ in CD46+ explants, which was not observed in the absence of IFNy (Fig. 9i, j), suggesting either IFN $\gamma$ or other inflammatory cytokines that are induced by IFN $\gamma$ (e.g., IL-6) may lead to greater STAT3 expression [60]. Together, these results demonstrate that activation of STAT 

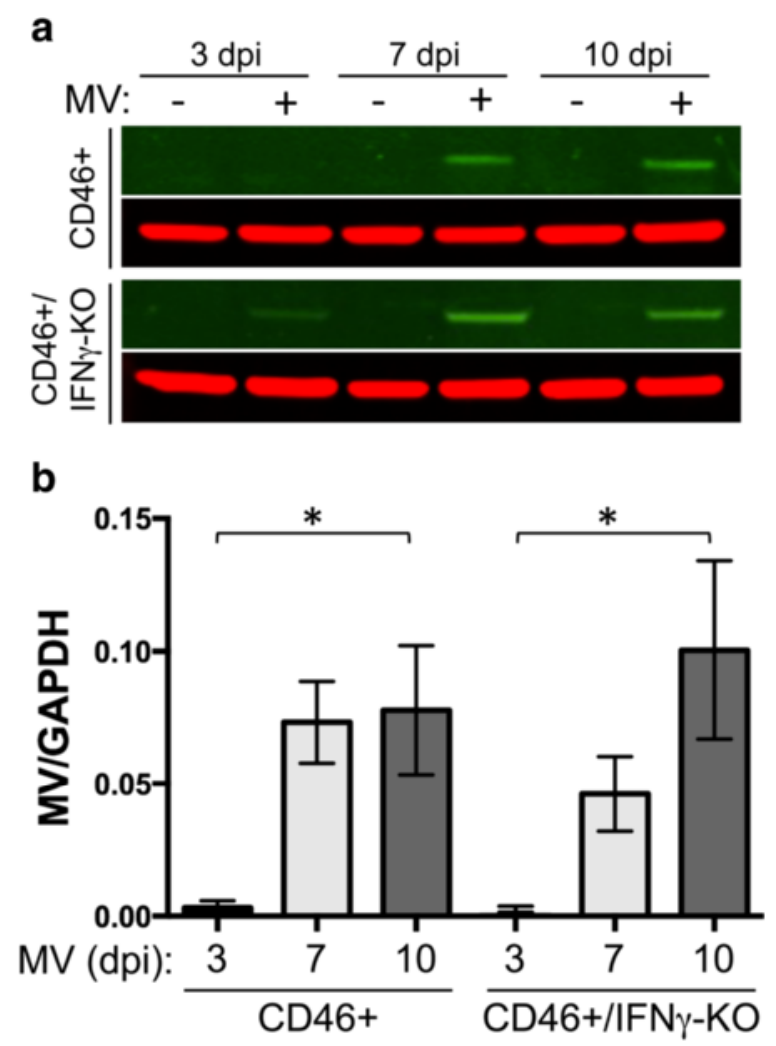

Fig. 7 IFNy does not reduce measles virus antigen in neonatal brain a. Lysates of brain tissue from CD46+ and CD46+/IFNY-KO neonates were analyzed by Western Blot for measles virus antigen. Control and MV-infected neonatal hippocampal lysates were collected at 3, 7, and 10 days post-infection (dpi) and probed with human polyclonal serum against MV and GAPDH as a loading control. b. Quantitation of MV levels normalized to GAPDH for each treatment condition in a. Statistical analysis was applied by two-way ANOVA $\left(n=4 ;{ }^{*} p<0.01\right)$

signaling molecules does not differ significantly early in infection (3 dpi), but that STAT1 and STAT2 phosphorylation occurs later infection in $\mathrm{CD} 46+$ and $\mathrm{CD} 46+/ \mathrm{IFN} \gamma$ $\mathrm{KO}$ explants. Thus, phosphorylation of STAT1 in the brain parenchyma may be influenced by cytokines other than IFN $\gamma$ during MV infection.

\section{Discussion}

This is the first study to directly examine the bystander effects of the anti-viral immune response on NSPC function in a model with neuron-restricted viral infection. Restricted NSPC proliferation and cell loss have been reported for various neurotropic viruses, but NSPCs were targets for the virus in many of these models [15, 17, 61]. Thus, the contributions from either the virus or the immune response to alterations in the NSPC pool are still unclear. In the CD46+ mouse model, NSPCs are spared from MV-infection. We found that NSPCs were protected by IFN $\gamma$ in MV-infected pups, whereas significant immature neuron loss was observed in both CD46+ and CD46+/IFN $\gamma-\mathrm{KO}$ pups. Mature neuron and glial cell numbers were unaltered. The proliferative index of the NSPC populations was unaffected while neurogenesis only declined at $10 \mathrm{dpi}$, suggesting that cell loss in both NSPC and early neuron populations is likely due to cell death and not due to changes in cell fate.

In the absence of IFN $\gamma$, the NSPC pool declined significantly at 7 and $10 \mathrm{dpi}$, with a trend toward lower NSPC numbers at $3 \mathrm{dpi}$ (Fig. 2). The earliest time point that we examined ( $3 \mathrm{dpi}$ ) is associated with a negligible number of T-cells in the brain but with notable natural killer cell infiltration (P. Ganesan, unpublished observations). It is possible that IFN $\gamma$ production by $\mathrm{T}$-cells is required to afford protection to the NSPC pool at later time points in infection. We also noted a lack of an effect on NSPC proliferation (Fig. 4), which we speculate is due to NSPCs remaining uninfected in our model. NSPCs infected with murine cytomegalovirus (MCMV) $[17,62]$, lymphocytic choriomeningitis virus (LCMV) [63], Japanese encephalitis virus (JEV) [61], and herpes simplex virus, type 1 (HSV-1) [15] display reduced proliferation that is associated with viral infection and replication in NSPCs. Instead, in our model, we suspect that the loss of uninfected NSPCs is due to cell death in the $\mathrm{CD} 46+/ \mathrm{IFN} \gamma-\mathrm{KO}$ pups. If NSPCs were undergoing a change in cell fate, we would have expected an increase in the number of neurons or glia, but instead we observed a reduced and unchanged cell number, respectively (Figs. 2 and 3), suggesting that the NSPCs are not being lost due to commitment to other cell types. Since direct viral infection cannot account for NSPC loss in our model system, one possibility is that the cytokine milieu that is released in the absence of IFNY is ultimately detrimental to the cells. A similar phenomenon has been characterized in models of antigen-induced arthritis, where IFN $\gamma-\mathrm{KO}$ mice suffer greater disease severity due to overexpression of IL-17 [64]. Additionally, an outstanding question that remains is how the presence of IFN $\gamma$ leads to protection of the NSPC pool in CD46+ neonates. IFN $\gamma$ treatment of NSPCs in vitro leads to decreased proliferation in the absence of other cytokines [65], which implies that IFNy does not afford protection to NSPCs by increasing proliferation in our model. Defining the anti-viral cytokine profile in CD46+ and CD46 $+/ \mathrm{IFN} \gamma$-KO pups may provide insight into the milieu that is required to maintain the NSPC pool during infection.

In CD46+ pups, young neurons are more susceptible to cell loss than mature neurons. Newly committed neuronal cells were lost at all time points post-infection in CD46+/IFN $\gamma$-KO pups and at 7 and $10 \mathrm{dpi}$ in CD46+ pups (Fig. 2). The production of new neurons, as measured by BrdU incorporation in CD24+ cells, declined 


\section{a. CD46+}

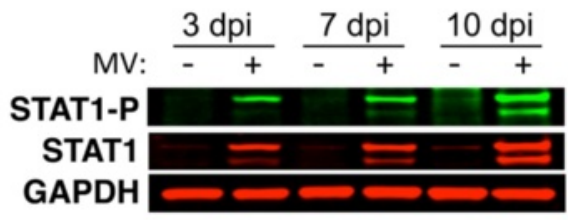

b
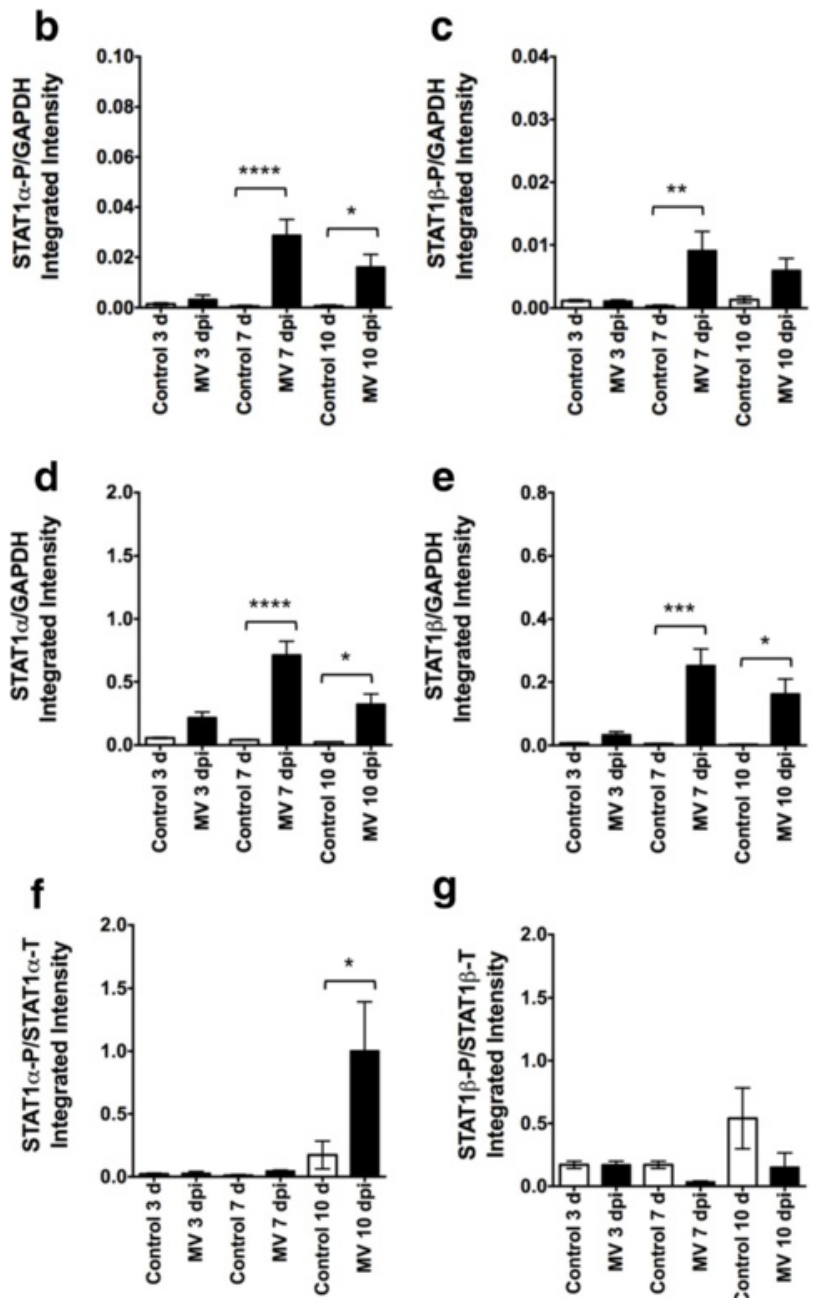

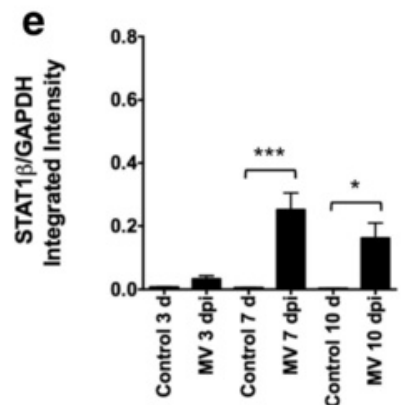

g

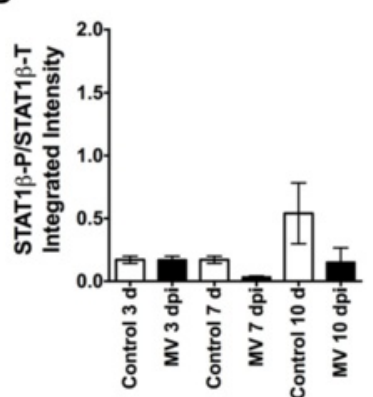

h. CD46+/IFN $\gamma-\mathrm{KO}$
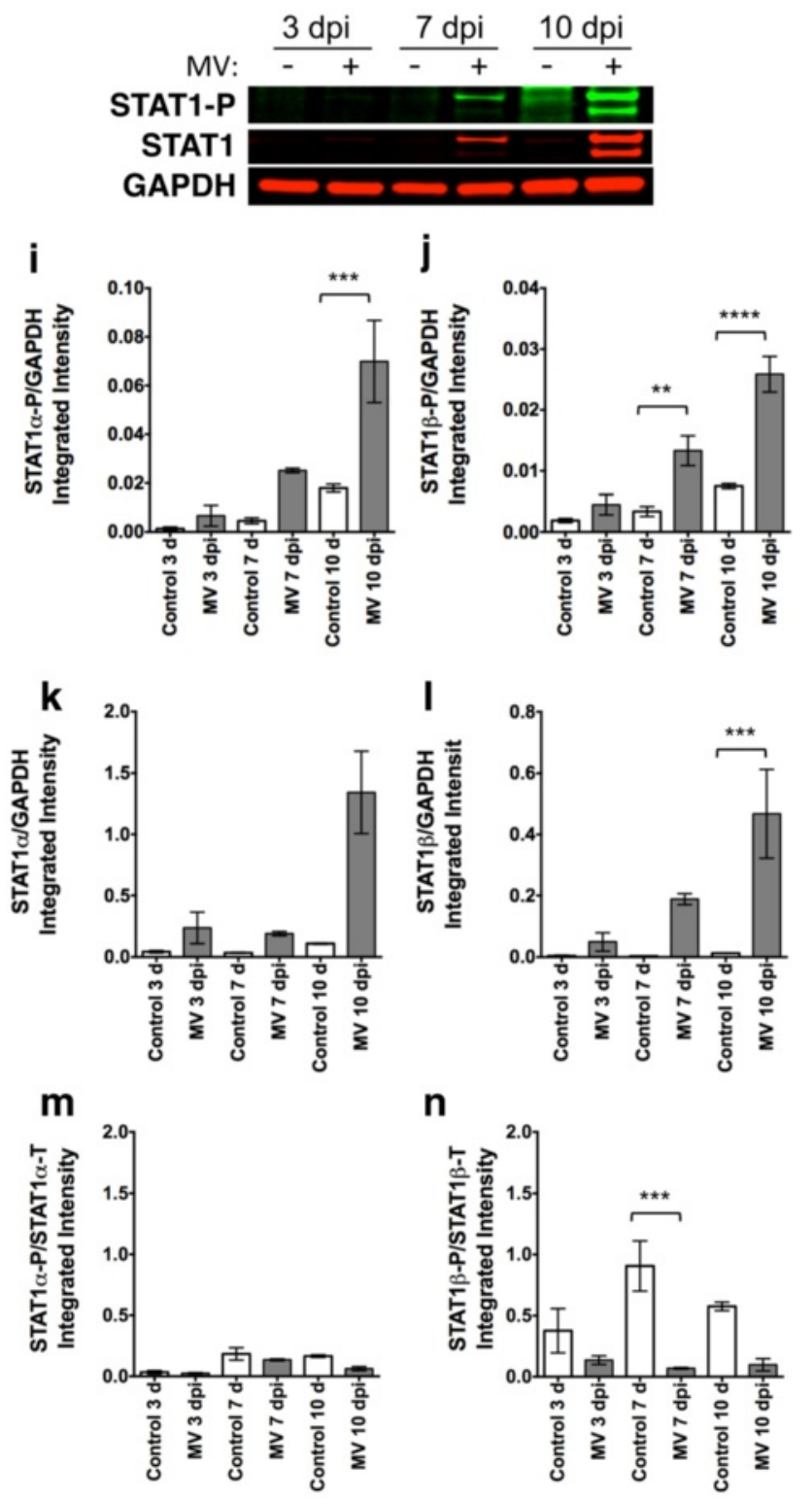

Fig. 8 STAT1 $a$ and STAT1 $\beta$ isoforms in the hippocampus are phosphorylated in the absence of IFNy during a viral infection. Lysates of hippocampal explants from CD46+ $(\mathbf{a}-\mathbf{g})$ and CD46+/IFNY-KO (h-n) control and MV-infected mice were analyzed by western blot for phosphorylated (activated) STAT1 (b, $\mathbf{c}, \mathbf{i}, \mathbf{j})$, and total STAT1 (d, e, $\mathbf{k}$, I) proteins. GAPDH was used as a protein loading control. Representative blots are shown in $\mathbf{a}$ and $\mathbf{b}$. Total levels of STAT1 a (upper band; $\mathbf{d}, \mathbf{k}$ ) and STAT1 $\beta$ (lower band; $\mathbf{e}, \mathbf{I}$ ) were significantly increased in MV-infected hippocampal explants from CD46+ pups (d, e) at 7 and 10 dpi and in CD46+/IFNy-KO pups (k, I) at 10 dpi. Phosphorylation of STAT1a (STAT1a-P; B, I) increased significantly in CD46+ explants at 7 and $10 \mathrm{dpi}$ (b) and CD46+/IFNY-KO explants at $10 \mathrm{dpi}$ (I). Phosphorylation of STAT1 $\beta$ (c, j) was increased in CD46+ explants at $7 \mathrm{dpi}$ only (c) and in CD46+/IFNY-KO explants and 7 and $10 \mathrm{dpi}$ (j). Protein ratios of STAT1a-P/STAT1a showed increased activation of phosphorylation of STAT1a-P at $10 \mathrm{dpi}$ in CD46+ mice (f), but no activation in CD46+/IFNY-KO mice (m). The protein ratios of STAT1 $\beta-P / S T A T 1 \beta$ showed decreased activation of phosphorylation during infection in CD46+/IFNY-KO mice (n), but not in CD46+ mice (g). Statistical analysis was applied by one-way ANOVA with multiple comparisons. $\left({ }^{* *} p<0.01,{ }^{* * *} p<0.001,{ }^{* * *} p<0.0001\right.$ significantly different uninfected versus MV-infected; $n=4$ )

only at $10 \mathrm{dpi}$ in both genotypes. Thus, a decrease in neurogenesis cannot account for the loss of early neurons at other time point during infection $(3$ and $7 \mathrm{dpi}$,
Fig. 4). One possibility is that early neurons are infected by $\mathrm{MV}$ as they fully differentiate, since the cells will begin to express NSE, and thus the human CD46 


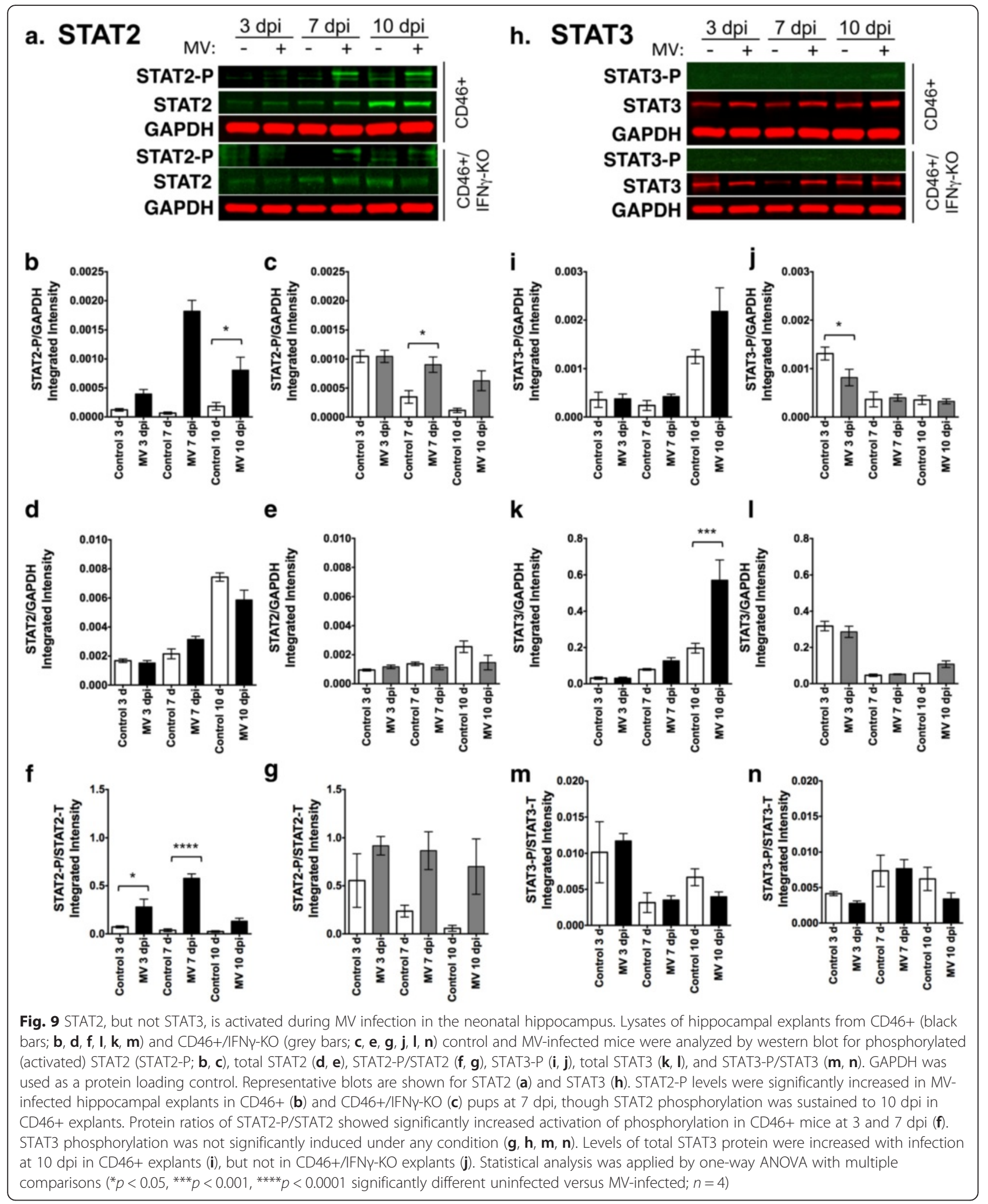

transgene, as MAP2 and BIII tubulin are induced [66]. In support of this possibility, NSPCs infected with Borna disease virus (BDV) and human immunodeficiency virus-1 (HIV-1) are unaffected by the viral infection. However, once cells are committed to the neuronal lineage and enter a post-mitotic state, apoptotic cell loss 
is observed $[16,67]$. This led us to also consider whether the subset of immature neurons lost during infection were actually MV-infected. We attempted to co-label our neural cells for MV proteins (not shown) to determine if CD24+ and DCX+ cells were MV-infected. Unfortunately, we were unable to successfully label our cell isolates for MV proteins by flow cytometry. Regardless, neuronal death is a common pathological outcome of viral infection [14]. It is likely that the reduction in neuronal cell number we observed was due to cell death and not due to NSPCs adopting a non-neuronal (glial) fate. Furthermore, adult CD46+ mice exhibit only limited apoptosis as a result of MV infection, which corresponds with successful viral control and survival, whereas a higher number TUNEL+ cells and death occurs in MVinfected CD46+ neonates at $7 \mathrm{dpi}$ and beyond (Fig. 5; $[19,50])$. Though adult CD46+ mice are capable of mediating non-cytolytic clearance of MV from CNS neurons, neonatal $\mathrm{CD} 46+$ mice cannot mediate noncytolytic clearance, as evidenced by persistent viral spread and widespread apoptosis in the brain parenchyma, despite T-cell infiltration [19, 49, 50]. Differences in non-cytolytic responses from neonatal and adult $\mathrm{T}$ cells are poorly understood. However, our findings imply that the neonatal immune response not only fails to control MV, but may also contribute to a loss of early neurons during MV infection. In support of this hypothesis, in vitro results demonstrate that embryonic CD46+ neurons are not killed by MV infection directly [68], suggesting that other factors contribute to loss of early neurons in vivo.

Western Blot analysis on hippocampal explants displayed changes in protein expression levels that corresponded with effects on cell number for nestin and DCX, but not for BIII-tubulin or GFAP (Fig. 6). The percentage of mature $\mathrm{NeuN}+$ cells was not significantly different in MV-infected explants compared to controls by flow cytometry (Fig. 2), but a significant reduction in BIII-tubulin expression was observed in MV-infected samples at $7 \mathrm{dpi}$. It is possible that the virus exerted regional effects on neuron survival and that hippocampal neurons were more susceptible to infection at $7 \mathrm{dpi}$ compared to other neurons elsewhere in the brain. Another possibility is that the effects on hippocampal neurons may not have been detectable in whole-brain isolates where neurons from the hippocampus are a small fraction of the total number of neurons isolated. Alternatively, Zimmer and colleagues observed that BIII-tubulin expression is downregulated at the transcriptional level by low doses of toxins, without frank cell death [69]. Thus, loss of BIII-tubulin may be indicative of stress on the hippocampal neurons in our model, but the stressor may not be sufficient to cause cell death. For GFAP staining, flow cytometry did not reveal significant changes in the number of GFAP+ cells (Fig. 3c, g) or in the intensity of the GFAP signal in whole-brain isolates (Fig. 3d, h). However, at 7 and $10 \mathrm{dpi}$, a trend toward an increased number of GFAP+ cells and greater GFAP intensity was observed, though this change was not significant. When we examined GFAP levels by Western Blot analysis in hippocampal explants, there was a increase in GFAP expression at $7 \mathrm{dpi}$ in MVinfected CD46+ mice compared to uninfected CD46+ mice (Fig. 6d) which was not observed in the absence of IFN $\gamma$. A possible explanation for the discrepancy in our data is that the hippocampus supports a high viral load in the CD46+ model. Therefore, the astrocytes in the hippocampus would be more likely to respond consistently to infected neurons, thus making changes in GFAP more readily detectable in this region.

Having observed that IFN $\gamma$ is protective for NSPCs (Fig. 1), we attempted to characterize which IFN $\gamma$-related signaling pathways are active in infected brain tissue. We also considered that Type I interferons (IFN $\alpha$ and IFN $\beta$ ) may be functioning as protective factors in the CD46+ pups. These IFNs also signal through STAT signaling pathways that are known to function in various CNS pathologies [70]. Furthermore, STAT1 signaling is important for viral control in adult CD46+ mice before $6 \mathrm{dpi}$, when the innate immune response is active [58]. We observed increased phosphorylation of STAT1 and STAT2, but not STAT3, in the hippocampi of MV-infected pups (Figs. 8 and 9). We had predicted that STAT1 signaling would be more pronounced in CD46+ pups, since the CD46 $+/$ IFN $\gamma$-KO pups would not have IFN $\gamma$ available to activate STAT1. STAT1 phosphorylation occurred in the absence of IFNy during MV infection, with $\mathrm{CD} 46+/ \mathrm{IFN} \gamma$ $\mathrm{KO}$ showing pronounced phosphorylation of both STAT1 isoforms when normalized to GAPDH versus uninfected controls (Fig. 8i, j). However, protein ratios for STAT1 $\alpha-\mathrm{P} /$ STAT $1 \alpha$ showed that only CD $46+$ mice increased regulation of phosphorylation during infection (Fig. 8f, m). Moreover, STAT1 $\beta-\mathrm{P} / \mathrm{STAT} 1 \beta$ ratios revealed decreased regulation of phosphorylation in the absence of IFN $\gamma$ (Fig. 8n). These results suggest that IFN $\gamma$ drives both increased phosphorylation of STAT1 $\alpha$, which is the transcriptionally active form of STAT1, during infection. Furthermore, although the relative level of phosphorylation of the dominant-negative isoform of STAT1 (STAT1 $\beta$ ) increased in both genotypes (Fig. 8c, j), the regulation of STAT1 $\beta-P$ phosphorylation declined in the absence of IFNy. One possibility is that other cytokines (e.g., IFN $\alpha / \beta)$ contribute to STAT1 phosphorylation during the anti-MV immune response, thus causing distinct patterns of STAT1 phosphorylation between genotypes. In CD46+ pups, STAT1 phosphorylation peaked at $7 \mathrm{dpi}$ and then declined by $10 \mathrm{dpi}$ (Fig. 8b-e). STAT2 activation also demonstrated a similar pattern to STAT1 (Fig. 9b), suggesting that a subset of signaling events was declining toward the end of the time course. Most of the CD46+ pups 
succumb to the infection between 9-12 dpi regardless of IFN $\gamma$ expression [49], and it is unclear why the CD46+ pups would demonstrate a decline in inflammatory signaling pathways when the virus is still present. However, future studies will examine the cytokine expression profile over the course of infection in CD46+ pups, which may provide an explanation as to the reduction in STAT1 and STAT2 signaling by $10 \mathrm{dpi}$.

Viral infections in the brain induce microglial and astrocytic activation, in addition to infiltration of peripheral immune cells. Widespread F4/80+ activated microglial staining was reported in MV-infected NSE-CD46+ pups at $7 \mathrm{dpi}$ [50], leaving open the possibility that the effects we observed on NSPCs and immature neurons were due to indirect effects on IFN $\gamma$-responsive microglia during infection. Activated microglia release proinflammatory factors that can positively or negatively impact neuronal function [71-73]. For example, IFN $\gamma$ activated microglia were shown to promote neurogenesis from NSPCs and to promote neuronal survival in vitro $[74,75]$. In our study, the loss of IFN $\gamma$ may have resulted in reduced microglial activation that compromised NSPC number in CD46+/IFN $\gamma-\mathrm{KO}$ mice but not CD46+ mice, due to a loss of protection or a loss of trophic support. We also observed a loss of immature neurons in both $\mathrm{CD} 46+$ and $\mathrm{CD} 46+/ \mathrm{IFN} \gamma-\mathrm{KO}$ pups, suggesting that IFN $\gamma$ does not protect this population (Fig. 1). Therefore, another possibility is that microglial activation is detrimental to early neuron survival, independent of IFNy. Microglial activation has been shown to cause neuronal apoptosis in the cortex, cerebellum, and hippocampus of BDV-infected neonatal rats in vivo [76, 77]. In our model, subpopulations of microglia may be more or less reliant on IFN $\gamma$ for activation and in our model this may have contributed to protection over NSPCs, but not early neurons, respectively.

Our studies are focused on the role of IFN $\gamma$ in viral pathogenesis in the CNS. However, IFNY is also expressed in many neurodegenerative disease states [78-80] where alterations in NSPC function are also observed. Though the pathology of these disease states varies, an understanding of the contribution of key cytokines, as well as combinations of multiple inflammatory mediators, will be necessary to fully understand the impact of the immune response on NSPC activity and survival.

\section{Conclusions}

This is the first study to demonstrate that IFNY protects NSPCs during a CNS viral infection. A transgenic mouse model of neuron-restricted MV infection was used to test the effects of the inflammatory environment created by the anti-viral immune response on NSPCs. Our results are the first to directly show that anti-viral immunity imposes bystander effects that compromise NSPC cell number, in the absence of IFN $\gamma$. It is still unclear what component of the immune response is damaging to NSPC function. Recent work by $\mathrm{Hu}$ and colleagues indicated that activated CD8+ T-cells, but CD4+ T-cells, reduced proliferation of MHC-matched NSPCs through the release of IFN $\gamma$ in vitro [81]. While we did not observe a decline in NSPC proliferation in our in vivo model, these results highlight the importance of considering the roles of specific immune cells in affecting NSPC function. It will be interesting to identify the immune cell subsets that are present during the 3-10 dpi window in order to clarify which immune cell population compromises NSPC and early neuron cell number. Overall, this study implicates IFN $\gamma$ as one cytokine involved in preserving NSPCs during viral infections and other inflammatory conditions.

\section{Additional file}

Additional file 1: Figure S1. Representative flow cytometry plots for neural cell identification. Brain homogenates from neonatal mice were analyzed via flow cytometry. Representative plots for each lgG isotype control and the respective neural cell antibody are shown. Top row: Forward/side scatter and 7-AAD negative (-) gates were applied to all samples. 2nd row: Markers for neural stem cells (nestin) and early neuronal markers (doublecortin, DCX). 3rd row: Markers for early neurons (CD24) and for mature neurons (NeuN). 4th Row: Markers for early glial progenitors (A2B5) and mature astrocytes (GFAP). (PDF 504 kb)

\section{Abbreviations}

ANOVA: Analysis of variance; ATCC: American Type Tissue Collection; BDV: Borna disease virus; BrdU: 5-bromo-2'-deoxyuridine; CNS: Central nervous system; Dpi: Day post-infection; DCX: Doublecortin; GAPDH: Glyceraldehyde 3-phosphate dehydrogenase; GFAP: Glial fibrillary acidic protein; HIV-1: Human immunodeficiency virus-1; KO: Knockout; HSV1: Herpes simplex virus, type 1; IFN: Interferon; IFNa: Interferon-alpha; IFNß: Interferon-beta; IFNY: Interferon-gamma; JEV: Japanese encephalitis virus; LCMV: Lymphocytic choriomeningitis virus; MAP2: Microtubule associated protein 2; MFI: Mean fluorescent intensity; MV: Measles virus; MCMV: Murine cytomegalovirus; MHC: Major histocompatibility complex; NSE: Neuron-specific enolase; NSPC: Neural stem/precursor cell; P: Postnatal day; PBS/tw: Phosphate-buffered saline and Tween-20; PFU: Plaque forming unit; SE: Standard error; STAT: Signaling transducer and activator of transcription; STAT-P: Phosphorylated signaling transducer and activator of transcription; TUNEL: Terminal deoxynucleotidyl transferase dUTP nick end labeling

\section{Competing interests}

The authors declare that they have no competing interests.

\section{Authors' contributions}

KNF and LOD conceived and designed the study and wrote the paper. KNF, $E L G, P G$, and AK performed the experiments. KNF, ELG, PG, and AK analyzed the data. All authors read and approved the final manuscript.

\section{Acknowledgements}

We are very grateful to Glenn Rall (Fox Chase Cancer Center) for providing the CD46+ and CD46+/IFNY-KO mice. We thank Manohar Mutnal (University of Minnesota) for advice with flow cytometry experiments, David Lee (BD Biosciences) for help with flow cytometry gating and BrdU analysis, and Jessica Posimo and Amanda Gleixner for technical advice with western blots. This research was funded by the Hunkele Dreaded Disease Award (LOD), the Samuel and Emma Winters Foundation (LOD), the Duquesne University Mylan School of Pharmacy (KNF, LOD), and R15-NS087606-01A1 (LOD). 


\section{Received: 2 October 2015 Accepted: 6 May 2016}

\section{Published online: 13 May 2016}

\section{References}

1. Schleede L, Bueter W, Baumgartner-Sigl S, Opladen T, Weigt-Usinger K, Stephan S, Smitka M, Leiz S, Kaiser O, Kraus V. Pediatric herpes simplex virus encephalitis: a retrospective multicenter experience. J Child Neurol. 2013;28:321-31.

2. Bonthius DJ. Lymphocytic choriomeningitis virus: a prenatal and postnatal threat. Adv Pediatr. 2009:56:75-86.

3. Tardieu M, Le Chenadec J, Persoz A, Meyer L, Blanche S, Mayaux MJ. HIV-1-related encephalopathy in infants compared with children and adults. French Pediatric HIV Infection Study and the SEROCO Group. Neurology. 2000;54:1089-95.

4. Douvoyiannis M, Litman N, Goldman DL. Neurologic manifestations associated with parvovirus B19 infection. Clin Infect Dis. 2009;48:1713-23.

5. Allsopp TE, Scallan MF, Williams A, Fazakerley JK. Virus infection induces neuronal apoptosis: a comparison with trophic factor withdrawal. Cell Death Differ. 1998:5:50-9.

6. Denizot M, Neal JW, Gasque P. Encephalitis due to emerging viruses: CNS innate immunity and potential therapeutic targets. J Infect. 2012;65:1-16.

7. Girard S, Couderc T, Destombes J, Thiesson D, Delpeyroux F, Blondel B. Poliovirus induces apoptosis in the mouse central nervous system. J Virol. 1999;73:6066-72.

8. Kaul M, Lipton SA. Experimental and potential future therapeutic approaches for HIV-1 associated dementia targeting receptors for chemokines, glutamate and erythropoietin. Neurotox Res. 2005;8:167-86.

9. Kaul M, Zheng J, Okamoto S, Gendelman HE, Lipton SA. HIV-1 infection and AIDS: consequences for the central nervous system. Cell Death Differ. 2005; 12 Suppl 1:878-92.

10. Kurt-Jones EA, Chan M, Zhou S, Wang J, Reed G, Bronson R, Arnold MM, Knipe DM, Finberg RW. Herpes simplex virus 1 interaction with Toll-like receptor 2 contributes to lethal encephalitis. Proc Natl Acad Sci U S A. 2004;101:1315-20.

11. Lyman M, Lloyd DG, Ji X, Vizcaychipi MP, Ma D. Neuroinflammation: the role and consequences. Neurosci Res. 2014;79:1-12.

12. Mutnal MB, Hu S, Little MR, Lokensgard JR. Memory T cells persisting in the brain following MCMV infection induce long-term microglial activation via interferon-gamma. J Neurovirol. 2011;17:424-37.

13. McKay R. Stem cells in the central nervous system. Science. 1997;276:66-71.

14. Das S, Basu A. Viral infection and neural stem/progenitor cell's fate: Implications in brain development and neurological disorders. Neurochem Int. 2011;59:357-66.

15. Chucair-Elliott AJ, Conrady C, Zheng M, Kroll CM, Lane TE, Carr DJ. Microglia-induced IL-6 protects against neuronal loss following HSV-1 infection of neural progenitor cells. Glia. 2014;62:1418-34.

16. Brnic D, Stevanovic V, Cochet M, Agier C, Richardson J, Montero-Menei CN, Milhavet $\mathrm{O}$, Eloit M, Coulpier M. Borna disease virus infects human neural progenitor cells and impairs neurogenesis. J Virol. 2012;86:2512-22.

17. Mutnal MB, Cheeran MC, Hu S, Lokensgard JR. Murine cytomegalovirus infection of neural stem cells alters neurogenesis in the developing brain. PLoS One. 2011;6, e16211.

18. Ruller CM, Tabor-Godwin JM, Van Deren Jr DA, Robinson SM, Maciejewski S, Gluhm S, Gilbert PE, An N, Gude NA, Sussman MA. Neural stem cell depletion and CNS developmental defects after enteroviral infection. Am J Pathol. 2012;180:1107-20.

19. Patterson CE, Lawrence DM, Echols LA, Rall GF. Immune-mediated protection from measles virus-induced central nervous system disease is noncytolytic and gamma interferon dependent. J Virol. 2002;76:4497-506.

20. Finke D, Brinckmann UG, ter Meulen V, Liebert UG. Gamma interferon is a major mediator of antiviral defense in experimental measles virus-induced encephalitis. J Virol. 1995;69:5469-74.

21. Stubblefield Park SR, Widness M, Levine AD, Patterson CE. T cell-, interleukin12-, and gamma interferon-driven viral clearance in measles virus-infected brain tissue. J Virol. 2011;85:3664-76.

22. Binder GK, Griffin DE. Interferon-gamma-mediated site-specific clearance of alphavirus from CNS neurons. Science. 2001;293:303-6.

23. Parra B, Hinton DR, Marten NW, Bergmann CC, Lin MT, Yang CS, Stohlman SA. IFN-gamma is required for viral clearance from central nervous system oligodendroglia. J Immunol. 1999;162:1641-7.

24. Hausmann J, Pagenstecher A, Baur K, Richter K, Rziha HJ, Staeheli P. CD8 T cells require gamma interferon to clear borna disease virus from the brain and prevent immune system-mediated neuronal damage. J Virol. 2005;79: 13509-18.
25. Richter K, Hausmann J, Staeheli P. Interferon-gamma prevents death of bystander neurons during CD8 T cell responses in the brain. Am J Pathol. 2009;174:1799-807.

26. Geiger KD, Nash TC, Sawyer S, Krahl T, Patstone G, Reed JC, Krajewski S, Dalton D, Buchmeier MJ, Sarvetnick N. Interferon-gamma protects against herpes simplex virus type 1-mediated neuronal death. Virology. 1997;238:189-97.

27. Yoneyama M, Shiba T, Hasebe S, Ogita K. Adult neurogenesis is regulated by endogenous factors produced during neurodegeneration. J Pharmacol Sci. 2011;115:425-32.

28. Ekdahl CT, Kokaia Z, Lindvall O. Brain inflammation and adult neurogenesis: the dual role of microglia. Neuroscience. 2009;158:1021-9.

29. Whitley RJ, Gnann JW. Viral encephalitis: familiar infections and emerging pathogens. Lancet. 2002;359:507-13.

30. Baron R, Nemirovsky A, Harpaz I, Cohen H, Owens T, Monsonego A. IFNgamma enhances neurogenesis in wild-type mice and in a mouse model of Alzheimer's disease. FASEB J. 2008;22:2843-52.

31. Johansson S, Price J, Modo M. Effect of inflammatory cytokines on major histocompatibility complex expression and differentiation of human neural stem/progenitor cells. Stem Cells. 2008;26:2444-54.

32. Barish ME, Mansdorf NB, Raissdana SS. Gamma-interferon promotes differentiation of cultured cortical and hippocampal neurons. Dev Biol. 1991; 144:412-23.

33. LaFerla FM, Sugarman MC, Lane TE, Leissring MA. Regional hypomyelination and dysplasia in transgenic mice with astrocyte-directed expression of interferon-gamma. J Mol Neurosci. 2000;15:45-59.

34. Kim IJ, Beck HN, Lein PJ, Higgins D. Interferon gamma induces retrograde dendritic retraction and inhibits synapse formation. J Neurosci. 2002;22:4530-9.

35. Ben-Hur T, Ben-Menachem O, Furer V, Einstein O, Mizrachi-Kol R, Grigoriadis $\mathrm{N}$. Effects of proinflammatory cytokines on the growth, fate, and motility of multipotential neural precursor cells. Mol Cell Neurosci. 2003;24:623-31.

36. Walter J, Honsek SD, Illes S, Wellen JM, Hartung HP, Rose CR, Dihne M. A new role for interferon gamma in neural stem/precursor cell dysregulation. Mol Neurodegener. 2011;6:18.

37. Wong G, Goldshmit Y, Turnley AM. Interferon-gamma but not TNF alpha promotes neuronal differentiation and neurite outgrowth of murine adult neural stem cells. Exp Neurol. 2004;187:171-7.

38. O'Donnell LA, Henkins KM, Kulkarni A, Matullo CM, Balachandran S, Pattisapu AK, Rall GF. Interferon gamma induces protective non-canonical signaling pathways in primary neurons. J Neurochem. 2015;135(2):309-322.

39. Tirotta E, Kirby LA, Hatch MN, Lane TE. IFN-gamma-induced apoptosis of human embryonic stem cell derived oligodendrocyte progenitor cells is restricted by CXCR2 signaling. Stem Cell Res. 2012;9:208-17.

40. Rall GF, Manchester M, Daniels LR, Callahan EM, Belman AR, Oldstone MB. A transgenic mouse model for measles virus infection of the brain. Proc Natl Acad Sci U S A. 1997:94:4659-63.

41. Reynolds BA, Weiss $S$. Generation of neurons and astrocytes from isolated cells of the adult mammalian central nervous system. Science. 1992;255:1707-10.

42. Panchision DM, Chen HL, Pistollato F, Papini D, Ni HT, Hawley TS. Optimized flow cytometric analysis of central nervous system tissue reveals novel functional relationships among cells expressing CD133, CD15, and CD24. Stem Cells. 2007:25:1560-70.

43. Schmid I, Krall WJ, Uittenbogaart CH, Braun J, Giorgi JV. Dead cell discrimination with 7-amino-actinomycin D in combination with dual color immunofluorescence in single laser flow cytometry. Cytometry. 1992;13:204-8.

44. Bilsland JG, Haldon C, Goddard J, Oliver K, Murray F, Wheeldon A, Cumberbatch J, McAllister G, Munoz-Sanjuan I. A rapid method for the quantification of mouse hippocampal neurogenesis in vivo by flow cytometry. Validation with conventional and enhanced immunohistochemical methods. J Neurosci Methods. 2006;157:54-63.

45. Posimo JM, Titler AM, Choi HJ, Unnithan AS, Leak RK. Neocortex and allocortex respond differentially to cellular stress in vitro and aging in vivo. PLoS One. 2013:8, e58596.

46. Gleixner AM, Pulugulla SH, Pant DB, Posimo JM, Crum TS, Leak RK. Impact of aging on heat shock protein expression in the substantia nigra and striatum of the female rat. Cell Tissue Res. 2014;357(1):43-54.

47. Leak RK, Castro SL, Jaumotte JD, Smith AD, Zigmond MJ. Assaying multiple biochemical variables from the same tissue sample. J Neurosci Methods. 2010;191:234-8.

48. Hagihara H, Toyama K, Yamasaki N, Miyakawa T. Dissection of hippocampal dentate gyrus from adult mouse. J Vis Exp. 2009;(33), e1543. doi:10.3791/1543. 
49. Lawrence DM, Vaughn MM, Belman AR, Cole JS, Rall GF. Immune responsemediated protection of adult but not neonatal mice from neuron-restricted measles virus infection and central nervous system disease. J Virol. 1999;73: 1795-801.

50. Manchester M, Eto DS, Oldstone MB. Characterization of the inflammatory response during acute measles encephalitis in NSE-CD46 transgenic mice. J Neuroimmunol. 1999;96:207-17.

51. Streit WJ, Walter SA, Pennell NA. Reactive microgliosis. Prog Neurobiol. 1999; 57:563-81.

52. Li L, Walker TL, Zhang Y, Mackay EW, Bartlett PF. Endogenous interferon gamma directly regulates neural precursors in the non-inflammatory brain J Neurosci. 2010;30:9038-50.

53. Wang J, Lin W, Popko B, Campbell IL. Inducible production of interferongamma in the developing brain causes cerebellar dysplasia with activation of the Sonic hedgehog pathway. Mol Cell Neurosci. 2004;27:489-96.

54. Kim SJ, Son TG, Kim K, Park HR, Mattson MP, Lee J. Interferon-gamma promotes differentiation of neural progenitor cells via the JNK pathway. Neurochem Res. 2007;32:1399-406.

55. Lum M, Croze E, Wagner C, McLenachan S, Mitrovic B, Turnley AM. Inhibition of neurosphere proliferation by IFNgamma but not IFNbeta is coupled to neuronal differentiation. J Neuroimmunol. 2009;206:32-8.

56. Cheng X, Jin G, Zhang X, Tian M, Zou L. Stage-dependent STAT3 activation is involved in the differentiation of rat hippocampus neural stem cells. Neurosci Lett. 2011;493:18-23.

57. Zhang SS, Liu MG, Kano A, Zhang C, Fu XY, Barnstable CJ. STAT3 activation in response to growth factors or cytokines participates in retina precursor proliferation. Exp Eye Res. 2005;81:103-15.

58. O'Donnell LA, Conway S, Rose RW, Nicolas E, Slifker M, Balachandran S, Rall GF. STAT1-independent control of a neurotropic measles virus challenge in primary neurons and infected mice. J Immunol. 2012;188:1915-23.

59. Zimmermann A, Trilling M, Wagner M, Wilborn M, Bubic I, Jonjic S, Koszinowski $U$, Hengel $\mathrm{H}$.

A cytomegaloviral protein reveals a dual role for STAT2 in IFN-\{gamma\} signaling and antiviral responses. J Exp Med. 2005;201:1543-53.

60. Sanceau J, Kaisho T, Hirano T, Wietzerbin J. Triggering of the human interleukin-6 gene by interferon-gamma and tumor necrosis factor-alpha in monocytic cells involves cooperation between interferon regulatory factor-1, NF kappa B, and Sp1 transcription factors. J Biol Chem. 1995;270:27920-31.

61. Das S, Basu A. Japanese encephalitis virus infects neural progenitor cells and decreases their proliferation. J Neurochem. 2008;106:1624-36.

62. Kosugi I, Shinmura Y, Kawasaki H, Arai Y, Li RY, Baba S, Tsutsui Y. Cytomegalovirus infection of the central nervous system stem cells from mouse embryo: a model for developmental brain disorders induced by cytomegalovirus. Lab Invest. 2000;80:1373-83.

63. Sharma A, Valadi N, Miller AH, Pearce BD. Neonatal viral infection decreases neuronal progenitors and impairs adult neurogenesis in the hippocampus. Neurobiol Dis. 2002;11:246-56.

64. Irmler IM, Gajda M, Brauer R. Exacerbation of antigen-induced arthritis in IFN-gamma-deficient mice as a result of unrestricted IL-17 response. J Immunol. 2007;179:6228-36.

65. Makela J, Koivuniemi R, Korhonen L, Lindholm D. Interferon-gamma produced by microglia and the neuropeptide PACAP have opposite effects on the viability of neural progenitor cells. PLoS One. 2010;5, e11091.

66. Oh J, You Y, Yun Y, Lee HL, Yoon do H, Lee $M$, et al.

67. McCarthy M, Vidaurre I, Geffin R. Maturing neurons are selectively sensitive to human immunodeficiency virus type 1 exposure in differentiating human neuroepithelial progenitor cell cultures. J Neurovirol. 2006;12:333-48.

68. Lawrence DM, Patterson CE, Gales TL, D'Orazio JL, Vaughn MM, Rall GF. Measles virus spread between neurons requires cell contact but not CD46 expression, syncytium formation, or extracellular virus production. J Virol. 2000;74:1908-18.

69. Zimmer B, Schildknecht S, Kuegler PB, Tanavde V, Kadereit S, Leist M. Sensitivity of dopaminergic neuron differentiation from stem cells to chronic low-dose methylmercury exposure. Toxicol Sci. 2011;121:357-67.

70. Campbell IL. Cytokine-mediated inflammation, tumorigenesis, and diseaseassociated JAK/STAT/SOCS signaling circuits in the CNS. Brain Res Brain Res Rev. 2005:48:166-77.

71. Das S, Basu A. Inflammation: a new candidate in modulating adult neurogenesis. J Neurosci Res. 2008;86:1199-208.

72. Ekdahl CT, Claasen JH, Bonde S, Kokaia Z, Lindvall O. Inflammation is detrimental for neurogenesis in adult brain. Proc Natl Acad Sci U S A. 2003: 100:13632-7.
73. Vallieres L, Campbell IL, Gage FH, Sawchenko PE. Reduced hippocampal neurogenesis in adult transgenic mice with chronic astrocytic production of interleukin-6. J Neurosci. 2002;22:486-92.

74. Butovsky O, Talpalar AE, Ben-Yaakov K, Schwartz M. Activation of microglia by aggregated beta-amyloid or lipopolysaccharide impairs MHC-II expression and renders them cytotoxic whereas IFN-gamma and IL-4 render them protective. Mol Cell Neurosci. 2005;29:381-93.

75. Butovsky O, Ziv Y, Schwartz A, Landa G, Talpalar AE, Pluchino S, Martino G, Schwartz M. Microglia activated by IL-4 or IFN-gamma differentially induce neurogenesis and oligodendrogenesis from adult stem/progenitor cells. Mol Cell Neurosci. 2006:31:149-60.

76. Weissenbock H, Hornig M, Hickey WF, Lipkin WI. Microglial activation and neuronal apoptosis in Bornavirus infected neonatal Lewis rats. Brain Pathol. 2000;10:260-72

77. Ovanesov MV, Moldovan K, Smith K, Vogel MW, Pletnikov MV. Persistent Borna Disease Virus (BDV) infection activates microglia prior to a detectable loss of granule cells in the hippocampus. J Neuroinflammation. 2008;5:16.

78. Mastrangelo MA, Sudol KL, Narrow WC, Bowers WJ. Interferon-\{gamma\} differentially affects Alzheimer's disease pathologies and induces neurogenesis in triple transgenic-AD mice. Am J Pathol. 2009;175:2076-88.

79. Barcia C, Ros CM, Annese V, Gomez A, Ros-Bernal F, Aguado-Yera D, Martinez-Pagan ME, de Pablos V, Fernandez-Villalba E, Herrero MT. IFNgamma signaling, with the synergistic contribution of TNF-alpha, mediates cell specific microglial and astroglial activation in experimental models of Parkinson's disease. Cell Death Dis. 2011;2, e142.

80. Seifert HA, Collier LA, Chapman CB, Benkovic SA, Willing AE, Pennypacker KR. Pro-inflammatory interferon gamma signaling is directly associated with stroke induced neurodegeneration. J Neuroimmune Pharmacol. 2014;9:679-89.

81. Hu S, Rotschafer JH, Lokensgard JR, Cheeran MC. Activated CD8+ T lymphocytes inhibit neural stem/progenitor cell proliferation: role of interferon-gamma. PLoS One. 2014;9, e105219.

\section{Submit your next manuscript to BioMed Central and we will help you at every step:}

- We accept pre-submission inquiries

- Our selector tool helps you to find the most relevant journal

- We provide round the clock customer support

- Convenient online submission

- Thorough peer review

- Inclusion in PubMed and all major indexing services

- Maximum visibility for your research

Submit your manuscript at www.biomedcentral.com/submit
Ciomed Central 